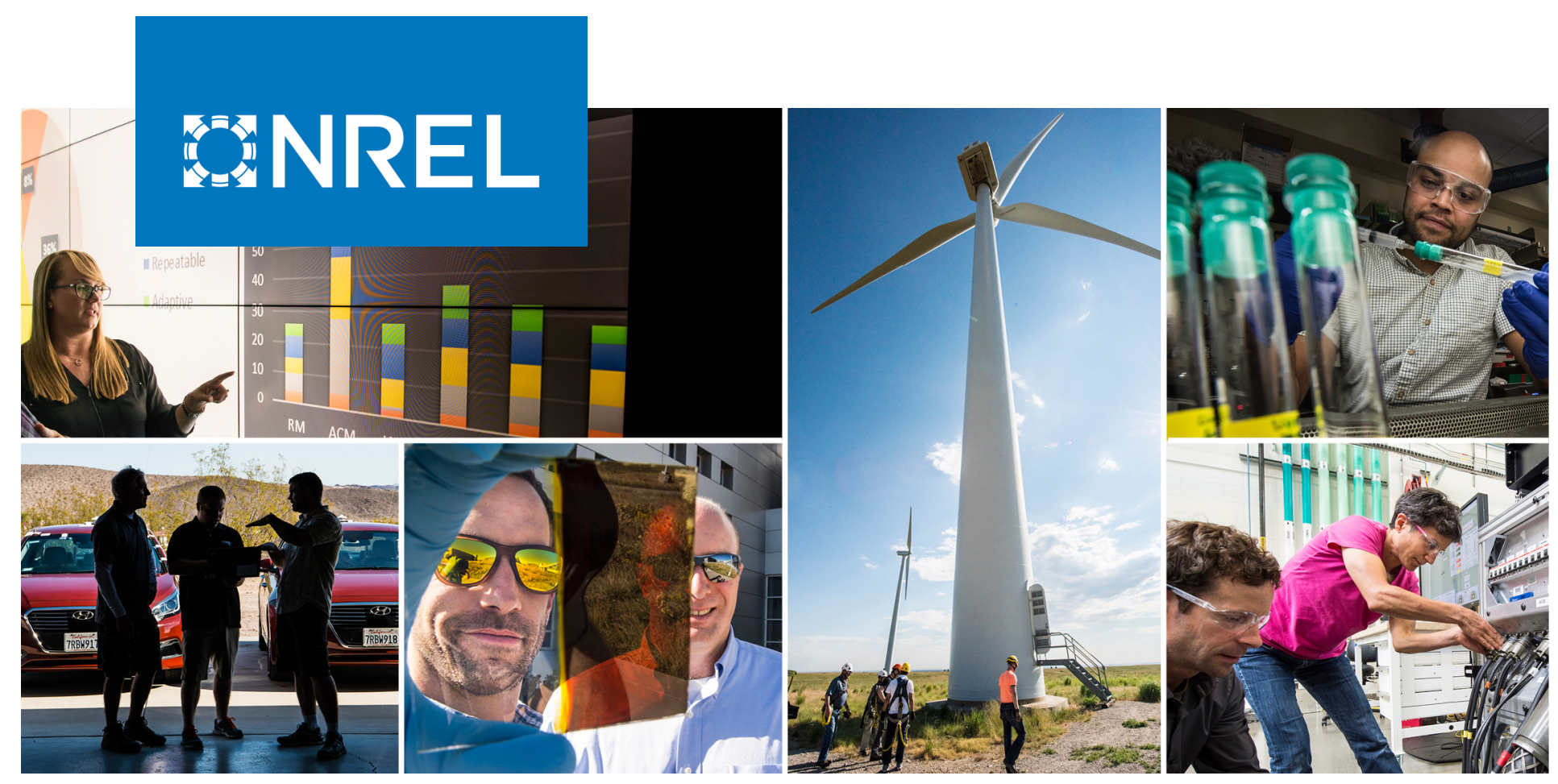

\title{
Technology Innovation Pathways for Distributed Wind Balance-of-System Cost Reduction
}

Parangat Bhaskar and Tyler Stehly

National Renewable Energy Laboratory

NREL is a national laboratory of the U.S. Department of Energy Office of Energy Efficiency \& Renewable Energy

Operated by the Alliance for Sustainable Energy, LLC

This report is available at no cost from the National Renewable Energy Laboratory (NREL) at www.nrel.gov/publications.

\section{Technical Report}

NREL/TP-5000-77452

April 2021 


\section{GNREL}

\section{Technology Innovation Pathways for Distributed Wind Balance-of-System Cost Reduction}

Parangat Bhaskar and Tyler Stehly

National Renewable Energy Laboratory

\section{Suggested Citation}

Bhaskar, Parangat, and Tyler Stehly. 2021. Technology Innovation Pathways for Distributed Wind Balance-of-System Cost Reduction. Golden, CO: National Renewable Energy Laboratory. NREL/TP-5000-77452. https://www.nrel.gov/docs/fy21osti/77452.pdf.

NREL is a national laboratory of the U.S. Department of Energy Office of Energy Efficiency \& Renewable Energy Operated by the Alliance for Sustainable Energy, LLC

This report is available at no cost from the National Renewable Energy Laboratory (NREL) at www.nrel.gov/publications.

Contract No. DE-AC36-08GO28308
Technical Report NREL/TP-5000-77452 April 2021

National Renewable Energy Laboratory 15013 Denver West Parkway Golden, CO 80401 303-275-3000 • www.nrel.gov 


\section{NOTICE}

This work was authored by the National Renewable Energy Laboratory, operated by Alliance for Sustainable Energy, LLC, for the U.S. Department of Energy (DOE) under Contract No. DE-AC36-08GO28308. Funding provided by the U.S. Department of Energy Office of Energy Efficiency and Renewable Energy Wind Energy Technologies Office. The views expressed herein do not necessarily represent the views of the DOE or the U.S. Government.

This report is available at no cost from the National Renewable Energy Laboratory (NREL) at www.nrel.gov/publications.

U.S. Department of Energy (DOE) reports produced after 1991 and a growing number of pre-1991 documents are available free via www.OSTI.gov.

Cover Photos by Dennis Schroeder: (clockwise, left to right) NREL 51934, NREL 45897, NREL 42160, NREL 45891, NREL 48097, NREL 46526.

NREL prints on paper that contains recycled content. 


\section{Acknowledgments}

The authors thank Bret Barker (Barker Advisory, contractor to the U.S. Department of Energy [DOE]), Patrick Gilman (DOE), and Eric Lantz (National Renewable Energy Laboratory [NREL]) for their strategic input and guidance in the development and execution of this work. We also thank Robert Preus (NREL), Owen Roberts (NREL), Josh Groleau (Pecos Wind Power), Mike Bergey (Bergey Windpower Company), and Jereme Kent (One Energy Enterprises LLC) for reviewing prior versions of this work. Finally, thanks to Sheri Anstedt (NREL) for editing support. Any remaining errors or omissions are the sole responsibility of the authors. 


\section{List of Acronyms}

BOS balance of system

CapEx capital expenditures

$\mathrm{kW}$

LandBOSSE

MW

NREL

ZPII

kilowatt

Land-based Balance of System Systems Engineering megawatt

National Renewable Energy Laboratory

zoning, permitting, interconnection, incentives 


\section{Executive Summary}

In the United States, distributed wind systems have the potential to serve rural or suburban homes, farms, and manufacturing facilities. This report defines representative distributed wind energy systems and uses bottom-up cost models to estimate distributed wind systems balance-ofsystem (BOS) costs and quantify system cost reductions and assess technologies that may enable cost reductions to better serve these markets. The BOS cost of a distributed wind project can contribute to up to half of the project's capital cost, and includes all costs associated with site preparation; wind turbine foundation; electrical infrastructure, management, and development; and tower erection/installation. The data and results detailed in the analysis are derived from 2019 commissioned distributed projects, representative industry data, and state-of-the-art modeling capabilities.

Throughout this report, the total BOS costs are reported in six categories for six theoretical representative distributed wind turbine projects. Figure ES1 summarizes the total BOS costs for residential (a 20-kilowatt [kW] machine), commercial (100-kW machine), midsize (650-kW machine), and large turbine scales $(1,500-\mathrm{kW}$ machine) for projects consisting of a single wind turbine. Figure ES2 reports total BOS costs for midsize and large turbine scales for projects consisting of five turbines.

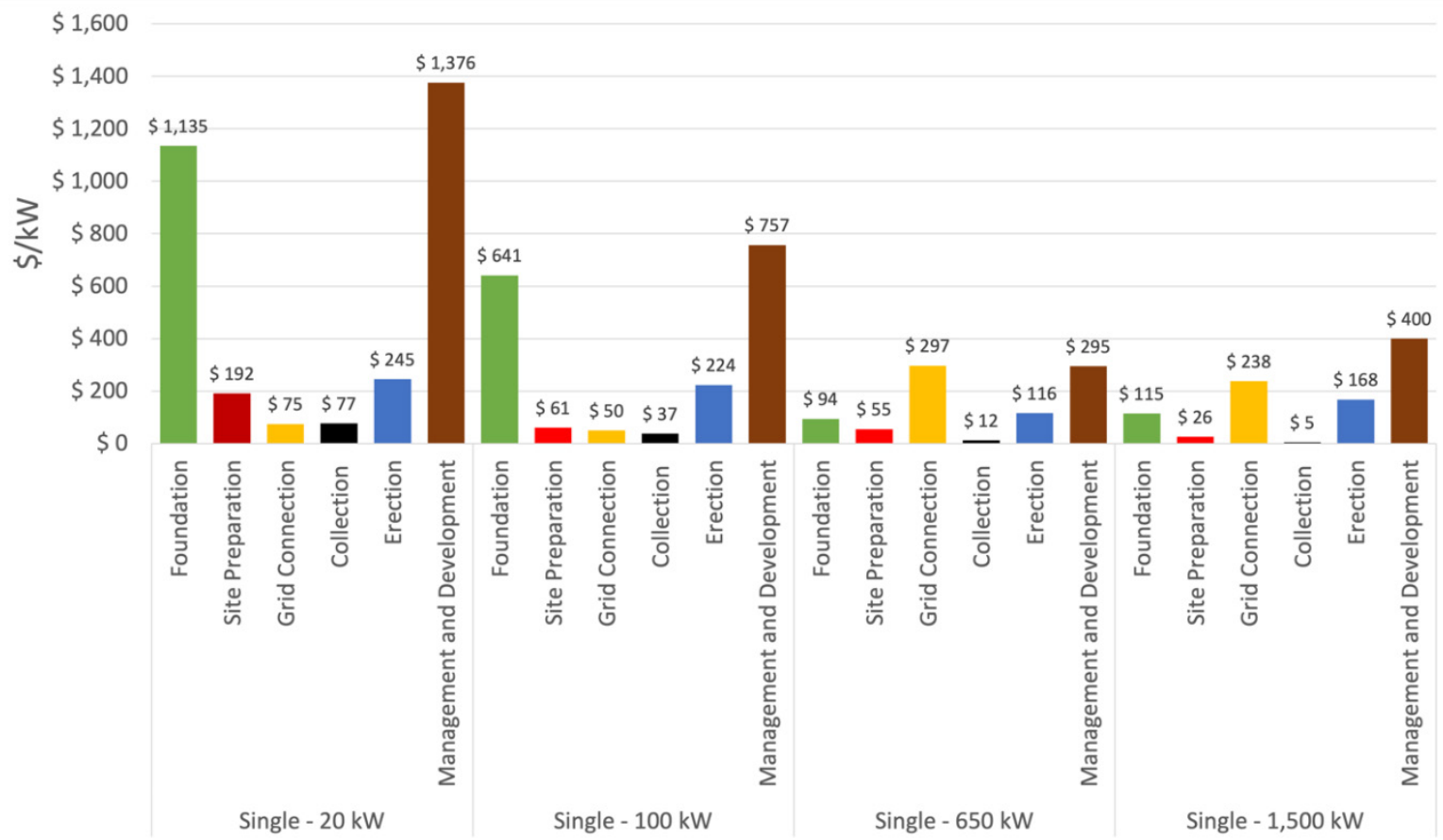

Figure ES1. Balance-of-system component cost estimates for residential, commercial, midsize, and large single-turbine distributed wind systems 


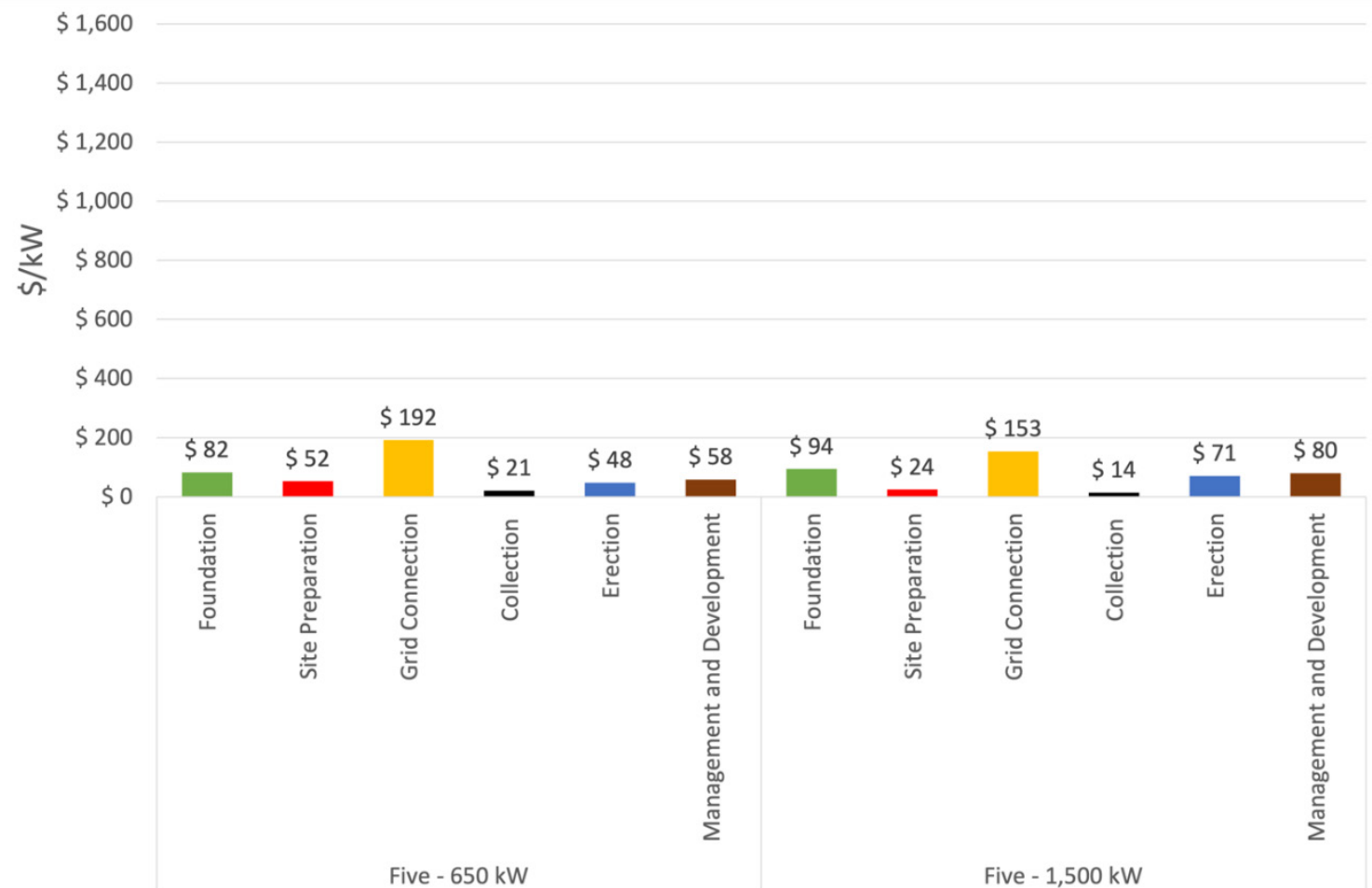

Figure ES2. Balance-of-system component cost estimates for midsize and large distributed wind systems consisting of five turbines

From the analysis detailed in this report, we derive the following key conclusions:

- For single-turbine distributed wind projects at all turbine sizes (i.e., residential- through large-scale turbines), management and development cost is consistently the largest driver; on average making up approximately $41 \%$ of total BOS cost

- The turbine foundation cost tends to be a larger portion of total BOS costs for smaller turbine sizes (i.e., residential- and commercial-scale wind turbines), attributing to about $36 \%$ of total BOS cost - primarily driven by the material-intensive nature of the foundations and the labor for installation distributed over a smaller system size

- As turbine size increases beyond commercial scale, the grid connection costs increase from around $3 \%$ of total BOS cost to approximately $30 \%$ for midsize and large turbines, requiring more advanced site preparation and electrical infrastructure equipment

- Adding more turbines - in this analysis five turbines as opposed to a single turbine - to the midsize and large distributed wind turbine projects reduces BOS costs by about $50 \%$, on a $\$ / \mathrm{kW}$ basis, from economies of project size

- The primary cost driver for the five-turbine midsize and large turbine scenarios is grid connection costs, comprising $42 \%$ and $35 \%$ of total BOS cost, respectively-increasing costs relate to overhead cable installation, procurement, and construction of a step-up transformer and switch gear, and medium-voltage cable terminations for larger systems.

Estimating the BOS costs with this bottom-up cost model approach is described further in this report. This capability helps identify cost drivers for a variety of distributed wind project scenarios as well as future research and development activities to further reduce these costs and lower the levelized cost of energy for distributed wind energy systems in the United States. 


\section{Table of Contents}

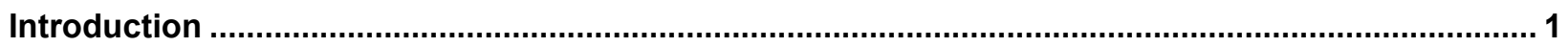

1 Distributed Wind Technology Characterization ..................................................................... 2

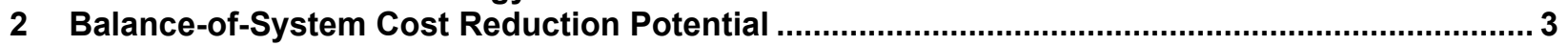

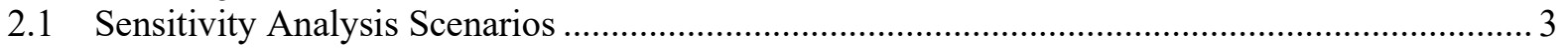

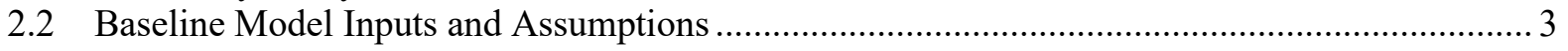

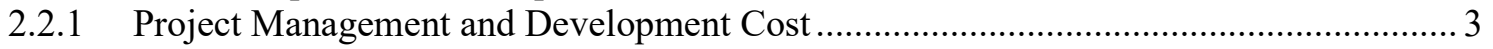

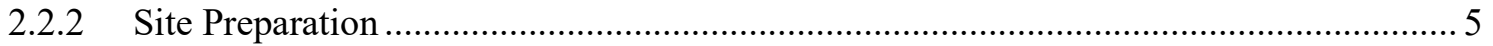

2.2.3 Wind Turbine Foundation ....................................................................... 7

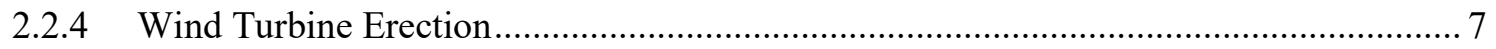

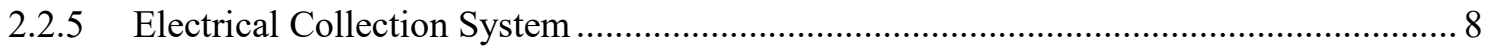

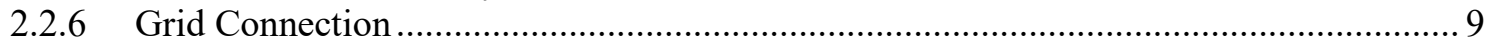

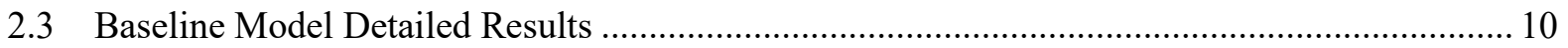

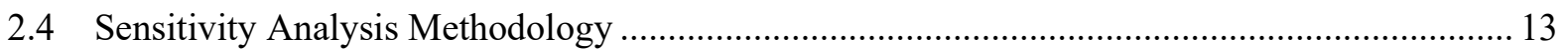

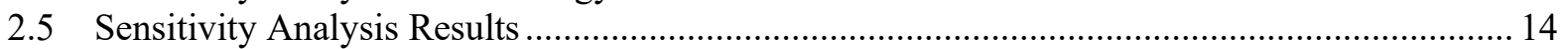

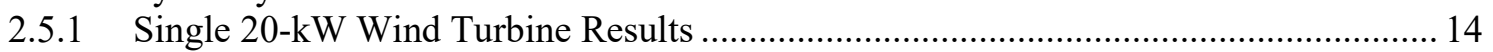

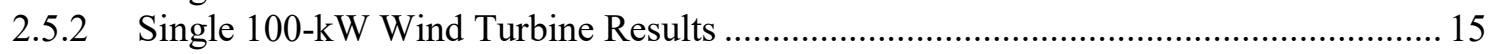

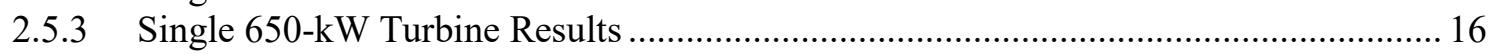

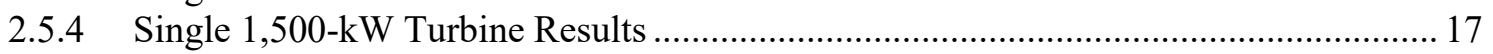

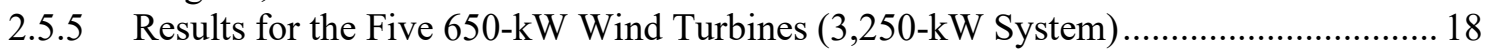

2.5.6 Results for the Five 1,500-kW Wind Turbines (7,500-kW System) ............................ 19

3 Technology Pathways for Balance-of-System Cost Reductions.............................................. 21

3.1 Project Management and Development …........................................................................ 21

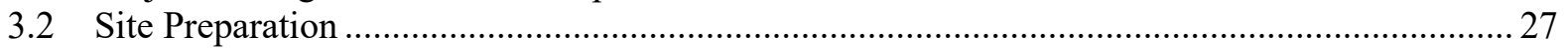

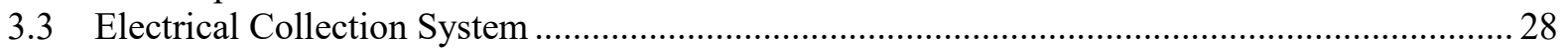

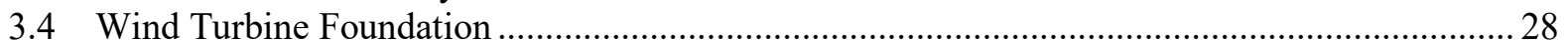

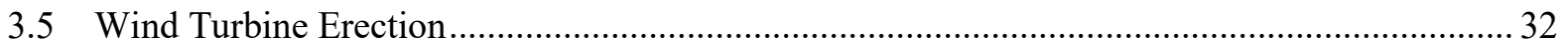

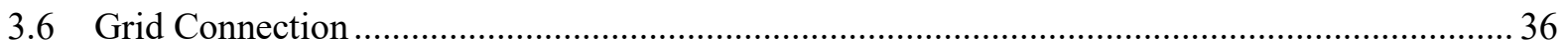

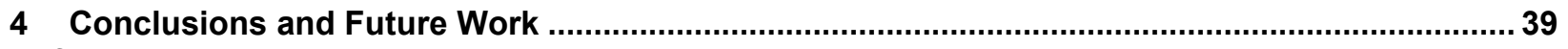

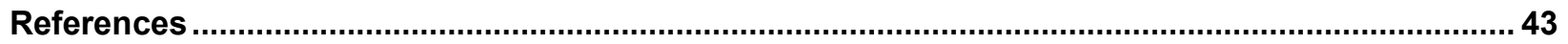




\section{List of Figures}

Figure ES1. Balance-of-system component cost estimates for residential, commercial, midsize, and large single-turbine distributed wind systems

\section{.. V}

Figure ES2. Balance-of-system component cost estimates for midsize and large distributed wind systems consisting of five turbines......

Figure 1. Baseline BOS CapEx $(\$ / \mathrm{kW})$ results calculated by LandBOSSE using inputs defined in Section

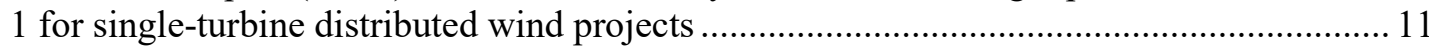

Figure 2. Baseline BOS CapEx $(\$ / \mathrm{kW})$ results calculated by LandBOSSE using inputs defined in Section 1 (broken down by cost of module) for single-turbine distributed wind projects .................. 11

Figure 3. Baseline BOS CapEx $(\$ / \mathrm{kW})$ results calculated by LandBOSSE using inputs defined in Section 1 for the five-turbine distributed wind projects................................................................... 12

Figure 4. Baseline BOS CapEx $(\$ / \mathrm{kW})$ results calculated by LandBOSSE using inputs defined in Section 1 (broken down by cost of module) for the five-turbine distributed wind projects ............... 12

Figure 5. Baseline total project BOS CapEx $(\$ / \mathrm{kW})$ comparison—single-turbine project vs. five-turbine project (650-kW machine and 1,500-kW machine) .......................................................... 13

Figure 6. Cost by type for the single-turbine project vs. the five-turbine project (650-kW machine and

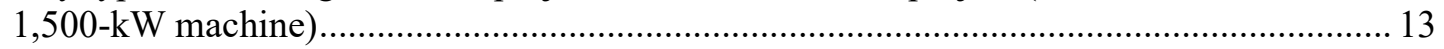

Figure 7. Balance-of-system cost impact for a single 20-kW (residential) wind turbine ......................... 15

Figure 8. Balance-of-system cost impact for a single 100-kW (commercial) wind turbine ...................... 16

Figure 9. Balance-of-system cost impact for a single 650-kW (midsize) wind turbine............................ 17

Figure 10. Balance-of-system cost impact for a single 1,500-kW (large) wind turbine ............................ 18

Figure 11. Balance-of-system cost impact for five $650-\mathrm{kW}$ wind turbines ........................................... 19

Figure 12. Balance-of-system cost impact for five 1,500-kW wind turbines ....................................... 20

Figure 13. ZPII's share of total project BOS CapEx (\%) (single-turbine projects) .................................. 22

Figure 14. Total number of days (average) taken to complete applications for ZPII at each project size

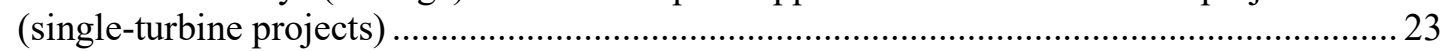

Figure 15. Average cost per day of ZPII application timeline at each project size (single-turbine projects)

Figure 16. Utility interconnection cost vs. number of days taken for processing a project's interconnection

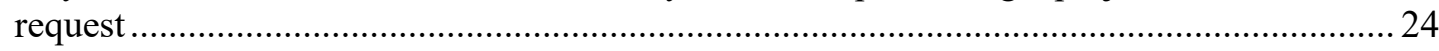

Figure 17. Impact on total ZPII cost resulting from a reduction in processing time (single residential and commercial-scale wind turbine projects) …............................................................... 25

Figure 18. Impact on total ZPII cost resulting from a reduction in processing time (single midsize and large-scale wind turbine projects) ............................................................................ 25

Figure 19. Impact on total project BOS CapEx from reducing ZPII processing time to $50 \%$ of the current average processing time (single-turbine projects) ......................................................... 27

Figure 20. Rendition of the Bergey $15-\mathrm{kW}$ wind turbine with a helical-anchored foundation. Image from

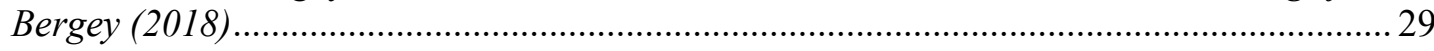

Figure 21. Wind turbine foundations on different soils; divided into three main load bearing classes.

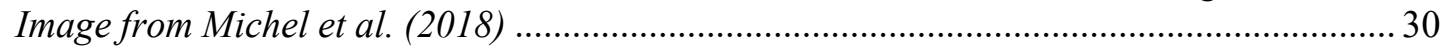

Figure 22. Rendition of the AirBASE foundation design that uses less concrete than the traditional shallow, spread-foot, reinforced concrete foundation. Image from HWS Concrete Towers (undated).....

Figure 23. Total foundation cost comparison: gravity (spread-foot) foundation vs. AirBASE technology.

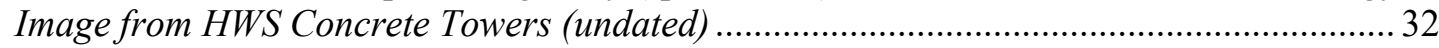

Figure 24. Most common wind turbine tower types available at the residential scale $(<100 \mathrm{~kW})$. Image

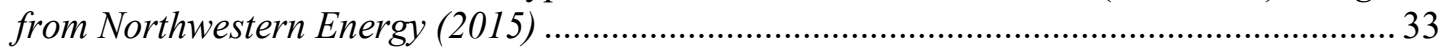

Figure 25. Cost breakdown of erecting a single $650-\mathrm{kW}$ wind turbine by type of cost........................... 34

Figure 26. Cost breakdown of erecting a single $1,500-\mathrm{kW}$ wind turbine by type of cost......................... 35 
Figure 27. Liftra's self-climbing crane capable of changing major wind turbine components. Photo from

$$
\text { Liftra (undated) }
$$

Figure 28. Transmission cost parts for new generation projects. Image from Andrade (2016) ................. 37

Figure 29. Increasing order of BOS cost contributors at each wind turbine scale......

\section{List of Tables}

Table 1. Discrete System Characterizations Considered for Analysis...................................................... 2

Table 2. Distributed Wind Size Classes........................................................................................... 2

Table 3. Summary of Defined Scenarios for Balance-of-System Sensitivity Analysis .............................. 3

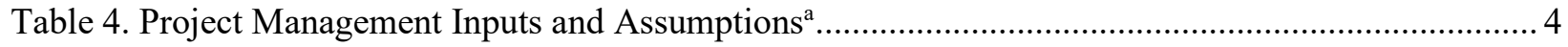

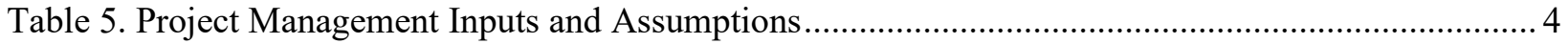

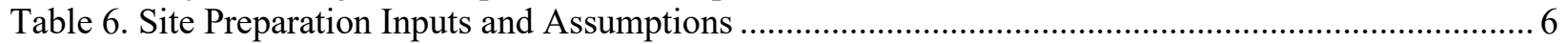

Table 7. Wind Turbine Foundation Inputs, Assumptions, and Intermediate Results ................................ 7

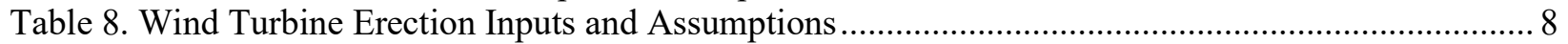

Table 9. Electrical Collection System Inputs and Assumptions ........................................................... 9

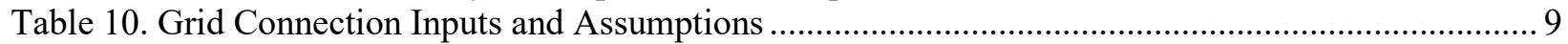

Table 11. Percent Reduction of Total Project BOS Cost Assuming 30\% Reduction in Respective BOS

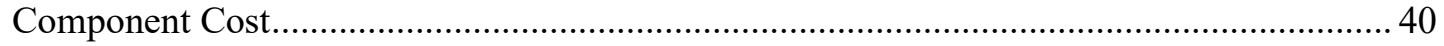

Table 12. Summary of Largest Cost Reduction Drivers of Balance-of-System Costs ............................. 40 


\section{Introduction}

Wind power is one of the fastest-growing sources of new electricity generation in the United States. U.S. wind power capacity additions equaled 9.158 megawatts (MW) in 2019, bringing the cumulative total to $105,591 \mathrm{MW}$. Despite this growth, the distributed wind market segment remains less robust in its application, with approximately $18 \mathrm{MW}$ of capacity additions in 2019 , equaling a cumulative total of 1,145 MW. Recent trends in distributed wind also differ from the distributed photovoltaics industry, which in 2019 installed approximately 5,000 MW for a total cumulative installed capacity of 30,300 MW at the end of 2019.

This exploratory analysis characterizes the balance-of-system (BOS) cost reduction opportunity for small, commercial, medium, and large distributed wind systems. To do this, we used the National Renewable Energy Laboratory's (NREL's) Land-based Balance of System Systems Engineering (LandBOSSE) model (Eberle et al. 2019). This model calculates the capital expenditures (CapEx) associated with installation and the system components (e.g., foundation and electrical infrastructure) other than the rotor nacelle assembly and tower. Then, building on the cost reduction potential assessment, we provide a more qualitative evaluation of prospective technology innovation concepts that may enable realization of those cost reductions for distributed wind systems. 


\section{Distributed Wind Technology Characterization}

Analysis results detailed in this report are contingent upon a detailed characterization or representation of distributed wind technologies. Even estimates of addressable resource potential require knowledge of potential hub heights and energy generation for wind turbines ranging from kilowatt $(\mathrm{kW})$ to megawatt scale. The technology characterizations, such as turbine rating, hub height, and rotor diameter for the baseline scenarios, are summarized in Table 1. These characteristics represent recent (2019) technology, as informed by empirical data and certified wind turbine equipment. In addition to defining the four specific wind turbine characteristics, the analysis considers different system sizes (i.e., project sizes comprising five turbines). The combinations of these single and multiturbine projects and their resulting system sizes are described in more detail in Section 2.1. We categorized the technology characterization into four specific system sizes: $20 \mathrm{~kW}$ (residential), $100 \mathrm{~kW}$ (commercial), $650 \mathrm{~kW}$ (midsize), and 1,500 $\mathrm{kW}$ (large), as defined in Lantz et al. (2016); see Table 2 for a detailed breakdown of the distributed wind class sizes.

Table 1. Discrete System Characterizations Considered for Analysis

\begin{tabular}{|c|c|c|}
\hline Turbine Rating $(\mathrm{kW})$ & Hub Height (meters $[\mathrm{m}])$ & Rotor Diameter $(\mathrm{m})$ \\
\hline $\mathbf{2 0}$ & 35 & 10 \\
\hline $\mathbf{1 0 0}$ & 45 & 24 \\
\hline $\mathbf{6 5 0}$ & 55 & 47 \\
\hline $\mathbf{1 , 5 0 0}$ & 80 & 77 \\
\hline
\end{tabular}

Table 2. Distributed Wind Size Classes

\begin{tabular}{c|c}
$\begin{array}{c}\text { Turbine } \\
\text { Technology Class }\end{array}$ & Size Range (kW) \\
\hline Residential scale & $\leq 20$ \\
\hline Commercial scale & $20<$ size $\leq 100$ \\
\hline Midsize scale & $100<$ size $<1,000$ \\
\hline Large scale & $\geq 1,000$ \\
\hline
\end{tabular}




\section{Balance-of-System Cost Reduction Potential}

To identify and quantify distributed wind system BOS cost reduction potential, we conducted a sensitivity analysis using Land-based Balance of System Systems Engineering (LandBOSSE). Specifically, we considered six scenarios that estimate total BOS capital expenditures based on changes in a single BOS category.

\subsection{Sensitivity Analysis Scenarios}

Four of the six scenarios assume a single-turbine installation-Scenarios 1 through 4 presented in Table 3-whereas Scenarios 5 and 6 simulate five turbines installed at the project site. The multiturbine installation scenarios - in this case, five turbines - are intended to not only capture the impact of system size on BOS cost but to assess the BOS cost reduction potential of distributing installation equipment cost among more than one turbine. The results of the sensitivity analysis are presented in Section 2.5.

Table 3. Summary of Defined Scenarios for Balance-of-System Sensitivity Analysis

\begin{tabular}{|c|c|c|c|}
\hline Scenario Number & Number of Turbines & Turbine Rating $(\mathrm{kW})$ & System Size $(\mathrm{kW})$ \\
\hline $\mathbf{1}$ & 1 & 20 & 20 \\
\hline $\mathbf{2}$ & 1 & 100 & 100 \\
\hline $\mathbf{3}$ & 1 & 650 & 650 \\
\hline $\mathbf{4}$ & 1 & 1,500 & 1,500 \\
\hline $\mathbf{5}$ & 5 & 650 & 3,250 \\
\hline $\mathbf{6}$ & 5 & 1,500 & 7,500 \\
\hline
\end{tabular}

\subsection{Baseline Model Inputs and Assumptions}

LandBOSSE requires a set of technology and BOS system characteristics inputs to calculate BOS costs. For example, if the project requires an access road for installation equipment to get to the site, road characteristics such as length, width, and thickness need to be input into the model. In this report, BOS costs are segmented into seven primary categories: project management, site preparation, foundation, erection, collection system, and grid connection. LandBOSSE requires input to the model to estimate the costs within the six categories. Additional details for each of these BOS cost categories are presented in the LandBOSSE documentation (Eberle et al. 2019). A summary of these categories and their input values to the model are presented in this section.

\subsubsection{Project Management and Development Cost}

The project management and development costs for each of the distributed wind scenarios includes construction management, engineering and design, and zoning and permitting. The total management costs equal the sum of all the costs presented in Table 4. 
Table 4. Project Management Inputs and Assumptions ${ }^{a}$

\section{Cost Category Notes}

Construction management

Other development and management costs

Engineering and design

1. Site assessment and characterization costs

2. Engineering studies/consulting/professional services

3. Inspections/oversight/miscellaneous testing

Zoning, permitting, interconnection, incentives

Costs associated with:

1. Zoning

2. Permitting (building/structural)

3. Permitting (electrical)

4. Permitting (Federal Aviation Administration)

5. Permitting (environmental)

6. Permitting (erosion and sediment control)

7. Utility interconnection

8. Incentives processing and transaction costs

9. Other - miscellaneous

${ }^{a}$ In the distributed wind version of LandBOSSE, project management and development cost is a lump-sum cost adder entered by the user in the inputs section of the model. Table 4 reports the baseline management and development costs $(\$ / \mathrm{kW})$ used in our analysis.

Table 5. Project Management Inputs and Assumptions

System Size

Management and Development Cost Input to Model $(\$ / k W)$

\begin{tabular}{|c|c|}
\hline Residential $(\mathbf{2 0} \mathbf{~ k W})$ & $\$ 1,376^{\mathrm{a}}$ \\
\hline Commercial $(\mathbf{1 0 0} \mathbf{~ k W})$ & $\$ 757^{\mathrm{a}}$ \\
\hline Midsize $(\mathbf{6 5 0} \mathbf{~ k W})$ & $\$ 295^{\mathrm{b}}$ \\
\hline Large $(\mathbf{1}, \mathbf{5 0 0} \mathbf{~ k W})$ & $\$ 400^{\mathrm{b}}$ \\
\hline $\mathbf{5}$ x Midsize $(\mathbf{5} \times \mathbf{6 5 0} \mathbf{~ k W})$ & $\$ 58^{\mathrm{c}}$ \\
\hline $\mathbf{5} \times$ Large $(\mathbf{5} \times \mathbf{1 , 5 0 0} \mathbf{~ k W})$ & $\$ 80^{\mathrm{c}}$ \\
\hline
\end{tabular}

${ }^{a}$ Cost obtained from the Pacific Northwest National Laboratory's 2017 report, "Benchmarking U.S. Small Wind Costs" (Orrell and Poehlman 2017). This cost driver comprises zoning, permitting, interconnection, incentives (ZPII), engineering and design, overhead and markup, and "other" costs.

${ }^{\mathrm{b}}$ We obtained management and development cost numbers for mid and large size distributed wind projects from industry-reported proprietary costs. However, the sample size of the data used to derive management and development costs for the mid and large size turbines was very limited. We averaged the management and development costs of three projects (for the mid and large project sizes) that reported their costs.

${ }^{\mathrm{c}}$ Assuming the total management and development cost (\$/project) of a five-turbine project does not scale much from the baseline total management and development cost of a single turbine project. ${ }^{1}$

${ }^{1}$ The basis for this assumption relies on the fact that only a few line items in the management and development cost category scale with the number of turbines in a project. These line items include, but are not limited to, project insurance, quality assurance/quality control, site control and security, and so on. These particular costs comprise roughly $20 \%$ (or less) of the total management and development cost. 


\subsubsection{Site Preparation}

Preparing the site for distributed wind projects includes activities like conducting a land survey, clearing and grubbing, stripping and stockpiling soil, constructing roads, and so on. Various factors influence each of the steps in the process, which are primarily driven by the site and terrain complexity, regional location of the project, bearing pressure of the trailers, method of crane travel, distance to a quarry, crane width, existing road crossings, site transport method, specifications for the road design, blade length, turbine spacing, number of turbines, and turbine rating. The parameters that influence the costs of each underlying site preparation process are grouped into four major categories: engineering hours, person hours, equipment hours, and quantity of materials. The final site preparation costs are then computed for labor, fuel, equipment, and materials based on the prices associated with each of these goods. A summary of the site preparation assumptions for the baseline is presented in Table 6 . 
Table 6. Site Preparation Inputs and Assumptions

\begin{tabular}{|c|c|c|c|c|c|c|}
\hline \multirow[b]{2}{*}{ Input Category } & \multicolumn{4}{|c|}{ Single-Turbine Scenarios } & \multicolumn{2}{|c|}{ Multiturbine Scenarios } \\
\hline & $\begin{array}{l}\text { 20-kW } \\
\text { System }\end{array}$ & $\begin{array}{l}100-k W \\
\text { System }\end{array}$ & $\begin{array}{l}650-k W \\
\text { System }\end{array}$ & $\begin{array}{l}1,500-k W \\
\text { System }\end{array}$ & $\begin{array}{l}3,250-k W \\
\text { System }\end{array}$ & $\begin{array}{l}7,500-k W \\
\text { System }\end{array}$ \\
\hline $\begin{array}{l}\text { Road width (feet } \\
\text { [ft]) }\end{array}$ & $12^{\mathrm{a}}$ & $12^{\mathrm{a}}$ & $20^{b}$ & $20^{b}$ & $20^{\mathrm{b}}$ & $20^{b}$ \\
\hline Road thickness (in) & 8 & 8 & 8 & 8 & 8 & 8 \\
\hline $\begin{array}{l}\text { Road length adder } \\
(\mathrm{m})\end{array}$ & $50^{c}$ & $100^{d}$ & $100^{d}$ & $100^{d}$ & $500^{e}$ & $500^{e}$ \\
\hline Road quality & $\begin{array}{l}\text { Dirt road } \\
\text { with crushed } \\
\text { stone }\end{array}$ & $\begin{array}{l}\text { Dirt road } \\
\text { with crushed } \\
\text { stone }\end{array}$ & $\begin{array}{l}\text { Paved } \\
\text { road }\end{array}$ & $\begin{array}{l}\text { Paved } \\
\text { road }\end{array}$ & $\begin{array}{l}\text { Paved } \\
\text { road }\end{array}$ & $\begin{array}{l}\text { Paved } \\
\text { road }\end{array}$ \\
\hline $\begin{array}{l}\text { Percentage of } \\
\text { roads to be } \\
\text { constructed }(\%)^{\mathrm{f}}\end{array}$ & 100 & 100 & 100 & 100 & 100 & 100 \\
\hline $\begin{array}{l}\text { Site preparation } \\
\text { area }\left(\mathrm{m}^{2}\right)\end{array}$ & $0 \mathrm{~g}$ & $452^{\mathrm{h}}$ & $1,735^{\mathrm{h}}$ & $4,500^{\mathrm{h}}$ & $8,675^{\mathrm{h}}$ & $22,500^{\mathrm{h}}$ \\
\hline $\begin{array}{l}\text { Total road volume } \\
\qquad\left(\mathrm{m}^{3}\right)\end{array}$ & 40 & 76.3 & 245 & 245 & 1225 & 1,225 \\
\hline $\begin{array}{l}\text { Topsoil volume } \\
\left(\mathrm{m}^{3}\right)\end{array}$ & 48.6 & 59.1 & 173 & 449 & 867 & 2,250 \\
\hline
\end{tabular}

${ }^{a}$ Road width for small-scale turbines set at 12 -feet (ft) wide to fit truck cranes. The construction of a dirt road is not common for the sub 20-kW wind turbine project. Truck cranes drive on unimproved grounds when the ground conditions are ideal. In wet ground conditions, fieldwork may get postponed. However, constructing a dirt road is not unheard of. In locations with higher annual precipitation, constructing a dirt road allows a truck crane to access the project year-round for operation and maintenance activities. Therefore, for sake of comparison with the BOS cost of other turbine sizes, analysts included a dirt road in their analysis of the 20-kW wind turbine. This also helps visualize the share of the total BOS cost comprising site preparation and road construction; and thus, assess the pros and cons of constructing a dirt road versus postponing fieldwork until ground conditions are ideal.

${ }^{\mathrm{b}}$ Road width for midsize and large-scale turbines set at $20 \mathrm{ft}$ to fit wider, crawler cranes.

${ }^{\mathrm{c}} \mathrm{A}$ very high-level industry unwritten rule for optimal placement of a small-scale wind turbine is to have the tip of the lowest blade $30 \mathrm{ft}(9 \mathrm{~m})$ above any physical obstacle (e.g., trees, poles, buildings) within a $500-\mathrm{ft}(152 \mathrm{~m})$

radius. Accordingly, road length selected here represents a lump-sum assumption that there are no obstructions within a $50-\mathrm{m}$ radius of the wind turbine.

${ }^{\mathrm{d}}$ Road length selected for the 100-, 650-, and 1,500-kW turbines was fixed at $100 \mathrm{~m}$ to assess the relative impact of road length on total project BOS cost. This $100 \mathrm{~m}$ also roughly accounts for setbacks that are, at a minimum, tip height distance from the closest obstruction (e.g., main road, buildings, electric poles).

${ }^{\text {e }}$ Assuming a $100-\mathrm{m}$ road length required per wind turbine.

f Some projects may not require construction of a new road to access the wind turbine (either because of soil and climate conditions permitting crane access to the turbine year-round, or the presence of existing road infrastructure).

${ }^{\mathrm{g}}$ Assuming no clearing and grubbing, site leveling, and so on is required for the 20-kW turbine.

${ }^{\mathrm{h}}$ Total wind turbine site preparation area (which includes clearing and grubbing, site leveling for crane pads, and so on) around each turbine set equal to swept area per turbine.

' Intermediate engineering result calculated by the site preparation module of LandBOSSE. 


\subsubsection{Wind Turbine Foundation}

Constructing tower foundations for a distributed wind project is largely driven by the foundation design, and includes excavating the site, putting down rebar and constructing a bolt cage, pouring concrete for the base, constructing the pedestal, and backfilling the foundation. Various factors influence each of these processes, but they are primarily driven by the number of wind turbines, duration of construction, regional location of the project, rotor diameter, hub height, turbine rating, whether a buoyant foundation design is required, seismic zone of the site, and type of tower technology being used. The dominant parameters that influence the foundation design, and therefore the foundation construction costs, are the soil type and foundation loads. The baseline wind turbine foundation assumptions for the six scenarios are summarized in Table 7.

Table 7. Wind Turbine Foundation Inputs, Assumptions, and Intermediate Results

\begin{tabular}{|c|c|c|c|c|c|c|}
\hline \multirow[b]{2}{*}{ Input Category } & \multicolumn{4}{|c|}{ Single-Turbine Scenarios } & \multicolumn{2}{|c|}{ Multiturbine Scenarios } \\
\hline & $\begin{array}{l}20-k W \\
\text { System }\end{array}$ & $\begin{array}{l}100-k W \\
\text { System }\end{array}$ & $\begin{array}{l}\text { 650-kW } \\
\text { System }\end{array}$ & $\begin{array}{l}1,500 \mathrm{~kW} \\
\text { System }\end{array}$ & $\begin{array}{l}3,250 \mathrm{~kW} \\
\text { System } \\
(5 \times 650 \\
\mathrm{kW})\end{array}$ & $\begin{array}{l}\mathbf{7 , 5 0 0 ~ k W} \\
\text { System } \\
(5 \times 1,500 \\
k W)\end{array}$ \\
\hline Foundation type & $\begin{array}{l}\text { Reinforced } \\
\text { concrete } \\
\text { spread } \\
\text { foot }^{3}\end{array}$ & $\begin{array}{l}\text { Reinforced } \\
\text { concrete } \\
\text { spread foot }\end{array}$ & $\begin{array}{l}\text { Reinforced } \\
\text { concrete } \\
\text { spread foot }\end{array}$ & $\begin{array}{l}\text { Reinforced } \\
\text { concrete } \\
\text { spread foot }\end{array}$ & $\begin{array}{l}\text { Reinforced } \\
\text { concrete } \\
\text { spread foot }\end{array}$ & $\begin{array}{l}\text { Reinforced } \\
\text { concrete } \\
\text { spread foot }\end{array}$ \\
\hline $\begin{array}{l}\text { Foundation depth } \\
\qquad(\mathrm{m})\end{array}$ & 1.5 & 2 & 2.3 & 2.6 & 2.3 & 2.6 \\
\hline $\begin{array}{l}\text { Concrete volume } \\
\qquad\left(\mathrm{m}^{3}\right)\end{array}$ & 23.9 & 50.6 & 62.7 & 192.7 & 341 & 901.6 \\
\hline $\begin{array}{l}\text { Mass of reinforced } \\
\text { steel used }^{\text {b }} \text { (short } \\
\text { ton) }\end{array}$ & 2.72 & 5.76 & 7.14 & 21.94 & 35.7 & 102.7 \\
\hline $\begin{array}{c}\text { Volume of dirt } \\
\text { excavated/backfilled } \\
\left.\text { (yard }{ }^{\mathrm{c}}\right)\end{array}$ & 69.50 & 184 & 240 & 598 & 1,200 & 2,990 \\
\hline \multicolumn{7}{|c|}{$\begin{array}{l}\text { a User input in LandBOSSE } \\
\text { b Intermediate (engineering) result calculated in LandBOSSE, and used for calculating cost of constructing turbine } \\
\text { foundation }\end{array}$} \\
\hline
\end{tabular}

\subsubsection{Wind Turbine Erection}

The traditional process of erecting a wind turbine starts with the delivery of parts, including the rotor, nacelle, and tower, which is typically installed with a crane. Turbine erection costs also include any civil work related to crane travel. The major drivers of the erection costs are the size, quantity, and type of cranes and the crews required for the project, which is influenced by the risk of short-term weather (specifically wind and lightning) delays and the size and weight of the tower and wind turbine components. The number of crane breakdowns required when moving the crane from turbine to turbine is also an important driver of erection costs - if necessary- for the larger wind turbine installations. For the multiturbine projects, analysts assumed that the 
terrain is fairly noncomplex and requires zero crane breakdowns. A summary of the turbine erection assumptions is reported in Table 8.

Table 8. Wind Turbine Erection Inputs and Assumptions

\begin{tabular}{|c|c|c|c|c|c|c|}
\hline \multicolumn{7}{|c|}{ Single- } \\
\hline Input Category & $\begin{array}{l}\text { 20-kW } \\
\text { System }\end{array}$ & $\begin{array}{l}100-k W \\
\text { System }\end{array}$ & $\begin{array}{l}\text { 650-kW } \\
\text { System }\end{array}$ & $\begin{array}{l}1,500-k W \\
\text { System }\end{array}$ & $\begin{array}{l}\text { 3,250-kW } \\
\text { System }\end{array}$ & $\begin{array}{l}7,500-k W \\
\text { System }\end{array}$ \\
\hline $\begin{array}{c}\text { Total } \\
\text { construction } \\
\text { time (months) }\end{array}$ & 1 & 1 & 3 & 3 & 5 & 5 \\
\hline $\begin{array}{l}\text { Nonerection }{ }^{a} \\
\text { wind delay } \\
\text { critical speed } \\
\text { (meters per } \\
\text { second) }\end{array}$ & 15 & 15 & 15 & 15 & 15 & 15 \\
\hline $\begin{array}{l}\text { Nonerection }{ }^{b} \\
\text { wind delay } \\
\text { critical height } \\
\text { (m) }\end{array}$ & 10 & 10 & 10 & 10 & 10 & 10 \\
\hline Crane width $(\mathrm{m})$ & 3 & 4 & 12.2 & 12.2 & 12.2 & 12.2 \\
\hline $\begin{array}{c}\text { Offloading } \\
\text { crane type and } \\
\text { capacity }\end{array}$ & N/A & $\begin{array}{l}\text { Forklift } \\
(20 \\
\text { tonnes })\end{array}$ & $\begin{array}{l}\text { Hydraulic } \\
(75 \\
\text { tonnes })\end{array}$ & $\begin{array}{l}\text { Hydraulic } \\
\text { (75 tonnes) }\end{array}$ & $\begin{array}{l}\text { Hydraulic } \\
(75 \\
\text { tonnes })\end{array}$ & $\begin{array}{l}\text { Hydraulic } \\
\text { (75 tonnes) }\end{array}$ \\
\hline $\begin{array}{l}\text { Topping crane } \\
\text { type and } \\
\text { capacity }\end{array}$ & $\begin{array}{l}\text { Hydraulic } \\
\text { (75 } \\
\text { tonnes) }\end{array}$ & $\begin{array}{c}\text { Hydraulic } \\
(230 \\
\text { tonnes })\end{array}$ & $\begin{array}{l}\text { Crawler } \\
(500 \\
\text { tonnes })\end{array}$ & $\begin{array}{c}\text { Crawler } \\
(1,500 \\
\text { tonnes })\end{array}$ & $\begin{array}{c}\text { Crawler } \\
(1,500 \\
\text { tonnes })\end{array}$ & $\begin{array}{c}\text { Crawler } \\
(1,500 \\
\text { tonnes })\end{array}$ \\
\hline
\end{tabular}

${ }^{a}$ Nonerection critical wind speed refers to the threshold wind speed beyond which all nonerection construction activities are put on hold until the wind speeds fall below this threshold.

${ }^{\mathrm{b}}$ Nonerection critical wind delay height is the height at which critical wind speeds are measured at.

${ }^{c}$ Crane selected by the wind turbine erection module in LandBOSSE

\subsubsection{Electrical Collection System}

Installing an electrical collection system for a distributed wind system involves preparing the site for the type of collection system being used (e.g., trenching) and then laying the conductors. The primary factors that influence the cost of the collection system are the number of electrical connections - which is a function of numerous input parameters - along with the type of collection system and the volume of cable required for the project. The major input parameters for collection system costs are therefore the site complexity, terrain complexity, electrical system losses, number of wind turbines, turbine rating, turbine model, average distance to the substation, regional location of the project, and turbine layout (for the multiturbine installations). The electrical collection system input assumptions are summarized in Table 9. All remaining electrical costs not considered in this module are captured in the grid connection module of LandBOSSE. The grid connection module includes costs related to wiring, switchgear (material and labor), the transformer (material and labor), and so on. 
Table 9. Electrical Collection System Inputs and Assumptions

\begin{tabular}{|c|c|c|c|c|c|c|}
\hline & \multicolumn{4}{|c|}{ Single-Turbine Scenarios } & \multicolumn{2}{|c|}{ Multiturbine Scenarios } \\
\hline Input Category & $\begin{array}{l}20-k W \\
\text { System }\end{array}$ & $\begin{array}{l}100-k W \\
\text { System }\end{array}$ & $\begin{array}{l}\text { 650-kW } \\
\text { System }\end{array}$ & $\begin{array}{l}1,500- \\
\text { kW } \\
\text { System }\end{array}$ & $\begin{array}{l}3,250-k W \\
\text { System }\end{array}$ & $\begin{array}{l}7,500-k W \\
\text { System }\end{array}$ \\
\hline $\begin{array}{c}\text { Grid } \\
\text { interconnection } \\
\text { voltage }\end{array}$ & $\begin{array}{c}\text { N/A } \\
\text { (cost is a } \\
\text { user } \\
\text { input) }\end{array}$ & $\begin{array}{c}13.8 \\
\text { kilovolts } \\
(\mathrm{kV})^{\mathrm{b}}\end{array}$ & $15 \mathrm{kV}$ & $15 \mathrm{kV}$ & $15 \mathrm{kV}$ & $15 \mathrm{kV}$ \\
\hline $\begin{array}{l}\text { Distance to grid } \\
\text { interconnection }\end{array}$ & $\begin{array}{c}\mathrm{N} / \mathrm{A} \\
\text { (cost is a } \\
\text { user } \\
\text { input) }{ }^{\mathrm{a}}\end{array}$ & $100 \mathrm{~m}$ & $100 \mathrm{~m}$ & $100 \mathrm{~m}$ & $\begin{array}{l}\text { Calculated by } \\
\text { LandBOSSE }\end{array}$ & $\begin{array}{l}\text { Calculated by } \\
\text { LandBOSSE }\end{array}$ \\
\hline
\end{tabular}

\subsubsection{Grid Connection}

The process of connecting to the electrical distribution grid for distributed wind applications varies by the size and number of turbines installed but generally includes performing a land survey, clearing and grubbing the area, implementing stormwater pollution measures, installing the poles, installing the generation tie conductor, and restoring the right of way. The costs of these processes are driven by the terrain complexity, line voltage, line length, and regional location of the project. And, as mentioned in the previous section, the grid connection module includes costs related to conductor installation, switchgear (material and labor), the transformer (material and labor), and so on. The grid connection and electrical collection modules make up the total electrical cost of a project. The assumptions for the baseline in this analysis are shown in Table 10.

Table 10. Grid Connection Inputs and Assumptions

\begin{tabular}{|c|c|c|c|c|c|c|}
\hline & \multicolumn{4}{c}{ Single-Turbine Scenarios } & \multicolumn{2}{c|}{ Multiturbine Scenarios } \\
\hline Input category & $\begin{array}{c}\mathbf{2 0 - k W} \\
\text { System }\end{array}$ & $\begin{array}{c}\mathbf{1 0 0 - k W} \\
\text { System }\end{array}$ & $\begin{array}{c}\mathbf{6 5 0 - k W} \\
\text { System }\end{array}$ & $\begin{array}{l}\mathbf{1 , 5 0 0 - k W} \\
\text { System }\end{array}$ & $\begin{array}{l}\mathbf{3 , 2 5 0 - k W} \\
\text { System }\end{array}$ & $\begin{array}{c}\mathbf{7 , 5 0 0 - k W} \\
\text { System }\end{array}$ \\
\hline $\begin{array}{c}\text { Interconnection } \\
\text { voltage (kV) }\end{array}$ & N/A & 13.8 & 15 & 15 & 15 & 15 \\
\hline $\begin{array}{c}\text { Distance to } \\
\text { interconnect } \\
\text { (meters) }\end{array}$ & N/A & 100 & 100 & 100 & 100 & 100 \\
\hline $\begin{array}{c}\text { Trench length } \\
\text { to interconnect } \\
\text { (kilometers) }\end{array}$ & 0.05 & 0.1 & 0.1 & 0.1 & $\begin{array}{c}\text { Calculated by } \\
\text { LandBOSSE }\end{array}$ & $\begin{array}{c}\text { Calculated by } \\
\text { LandBOSSE }\end{array}$ \\
\hline
\end{tabular}




\subsection{Baseline Model Detailed Results}

We ran LandBOSSE using the model inputs (and assumptions) defined in Section 2.2. Figures 1 through Figure 6 summarize the total project BOS costs and their respective cost breakdowns. As shown in the results, for single-turbine projects, the management and development cost are consistently one of the biggest BOS cost drivers. However, this cost driver's share of the total BOS cost drops significantly for multiturbine projects (Scenarios 5 and 6; Figure 5 and Figure 6). This drop is based on the assumption that the total management and development $\operatorname{cost}^{2}$ for a distributed wind project does not scale with the number of turbines in the project.

We also observed that wind turbine foundation cost is the second-biggest BOS cost driver at smaller project sizes (residential and commercial scales). For single-turbine projects with larger turbines (mid and large sizes), the primary cost drivers - in addition to the management and development cost—shift to turbine erection and grid connection costs. For multiturbine projects, management and development cost is no longer one of the primary BOS cost drivers. Instead, grid connection overtakes management and development to become the biggest share of a project's total BOS cost.

In Section 3, we identify and discuss factors that drive the cost of the six BOS components and provide examples of technological innovations that could reduce the impact of said factors.

\footnotetext{
${ }^{2}$ The management and development cost driver in this analysis comprises the following components (Table 3): construction management; engineering design; zoning, permitting, interconnection, and incentives (ZPII); and other development and management costs (miscellaneous costs).
} 


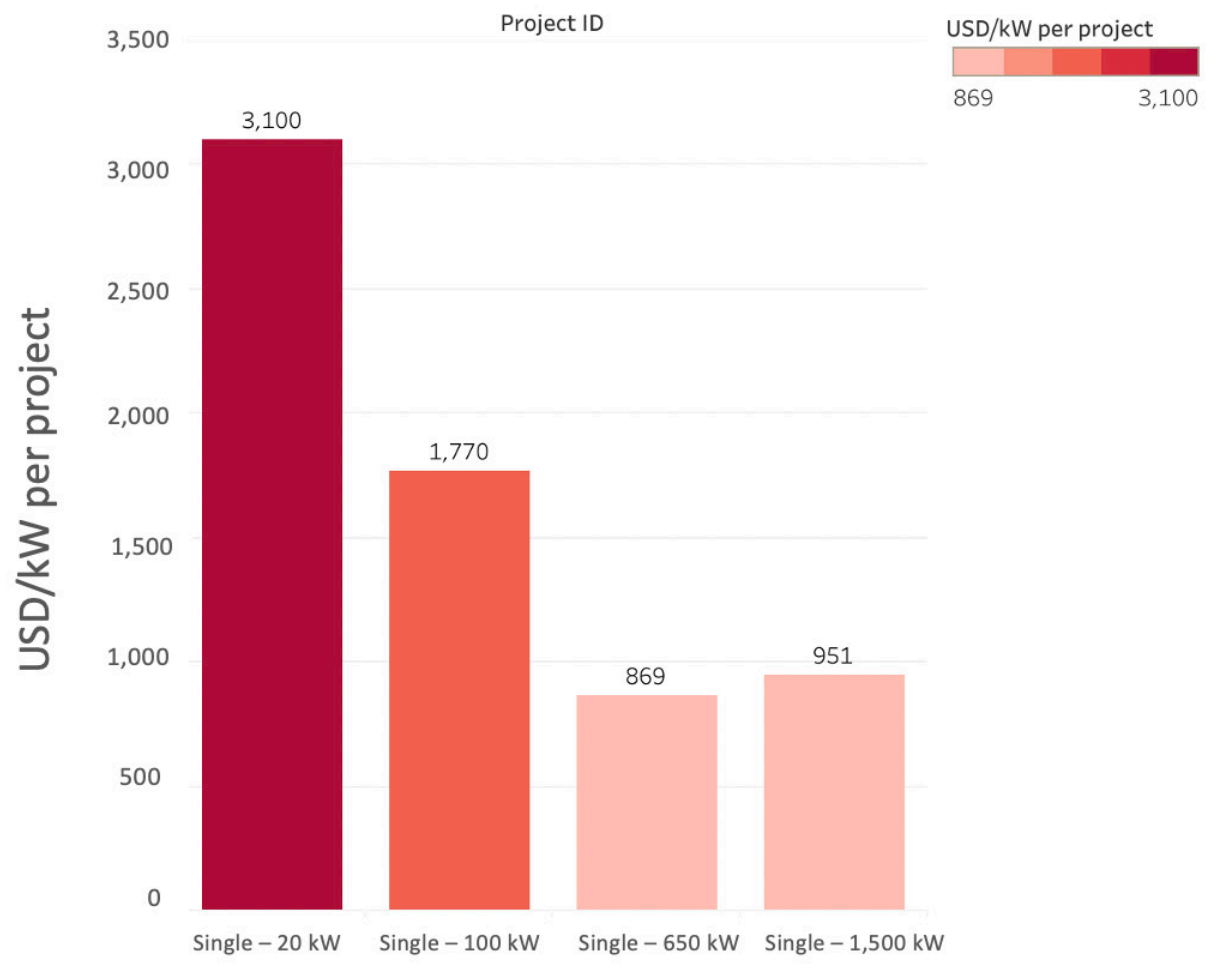

Figure 1. Baseline BOS CapEx $(\$ / \mathrm{kW})$ results calculated by LandBOSSE using inputs defined in Section 1 for single-turbine distributed wind projects

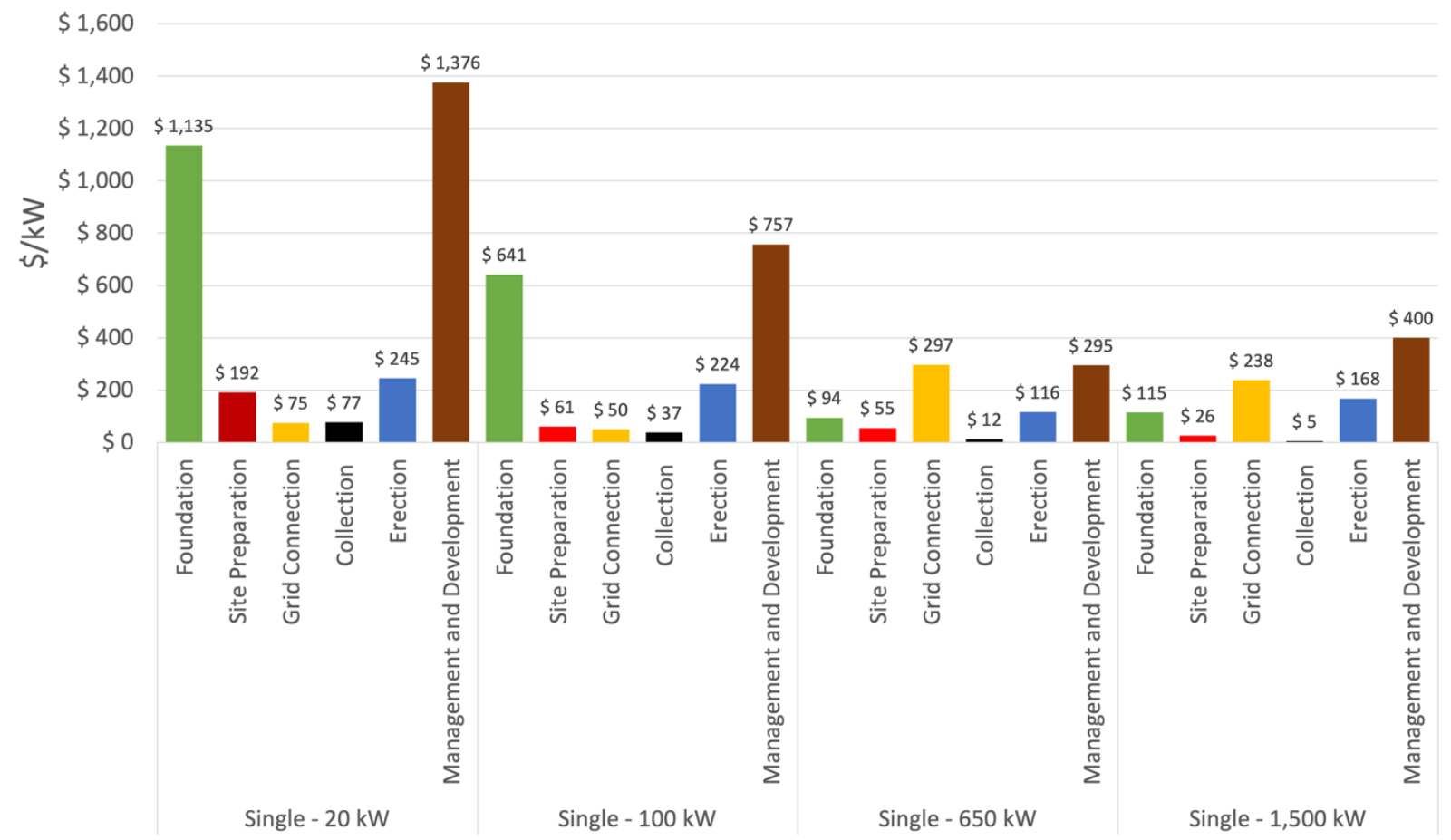

Figure 2. Baseline BOS CapEx $(\$ / \mathrm{kW})$ results calculated by LandBOSSE using inputs defined in Section 1 (broken down by cost of module) for single-turbine distributed wind projects 


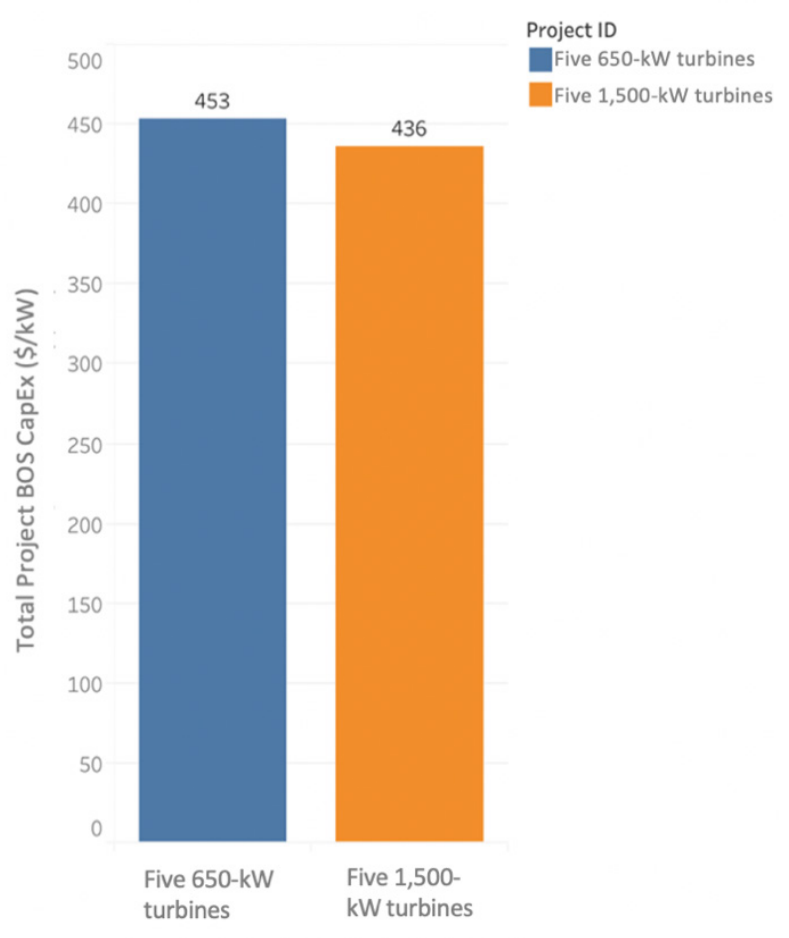

Figure 3. Baseline BOS CapEx (\$/kW) results calculated by LandBOSSE using inputs defined in Section 1 for the five-turbine distributed wind projects

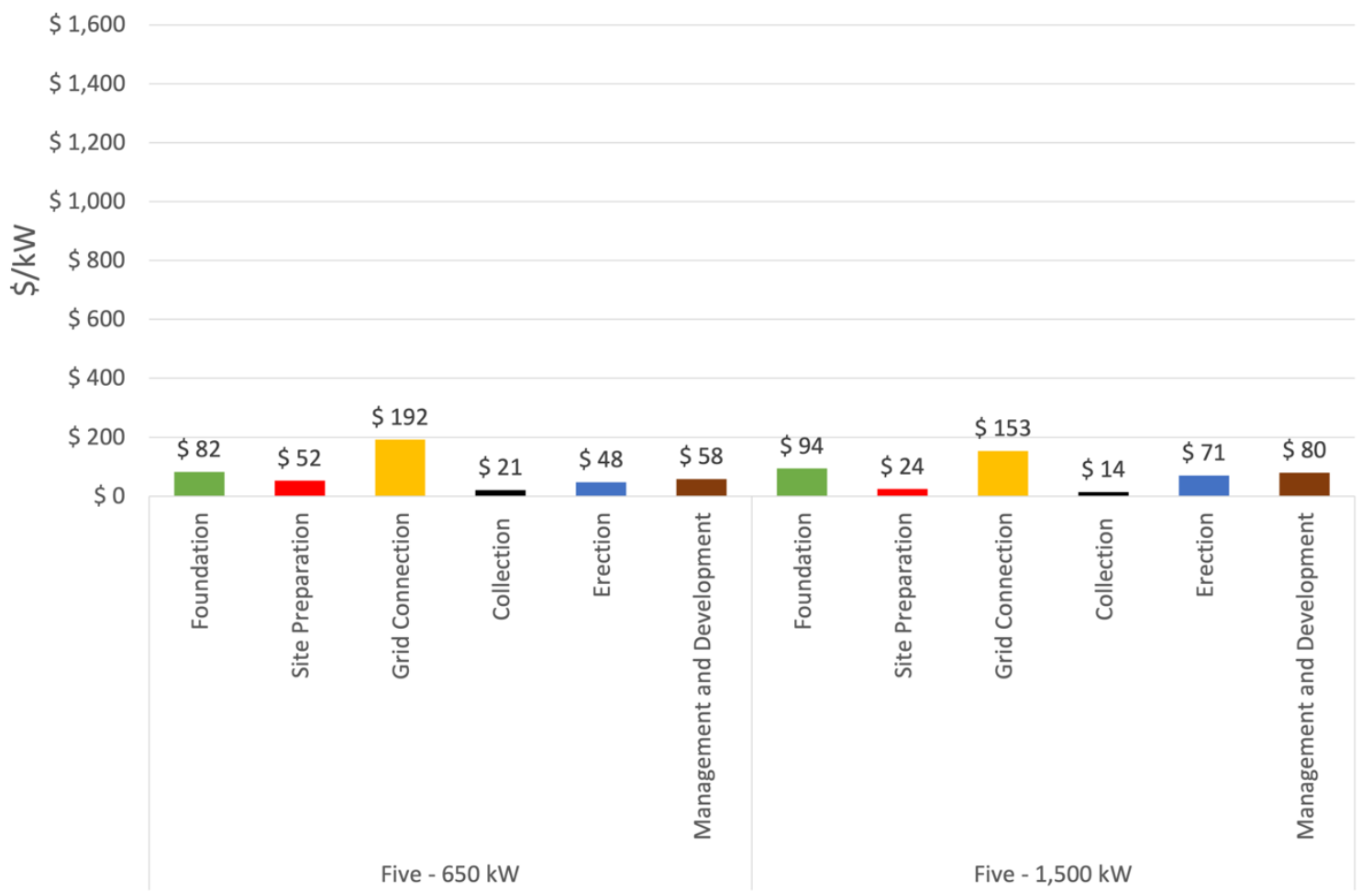

Figure 4. Baseline BOS CapEx (\$/kW) results calculated by LandBOSSE using inputs defined in Section 1 (broken down by cost of module) for the five-turbine distributed wind projects 


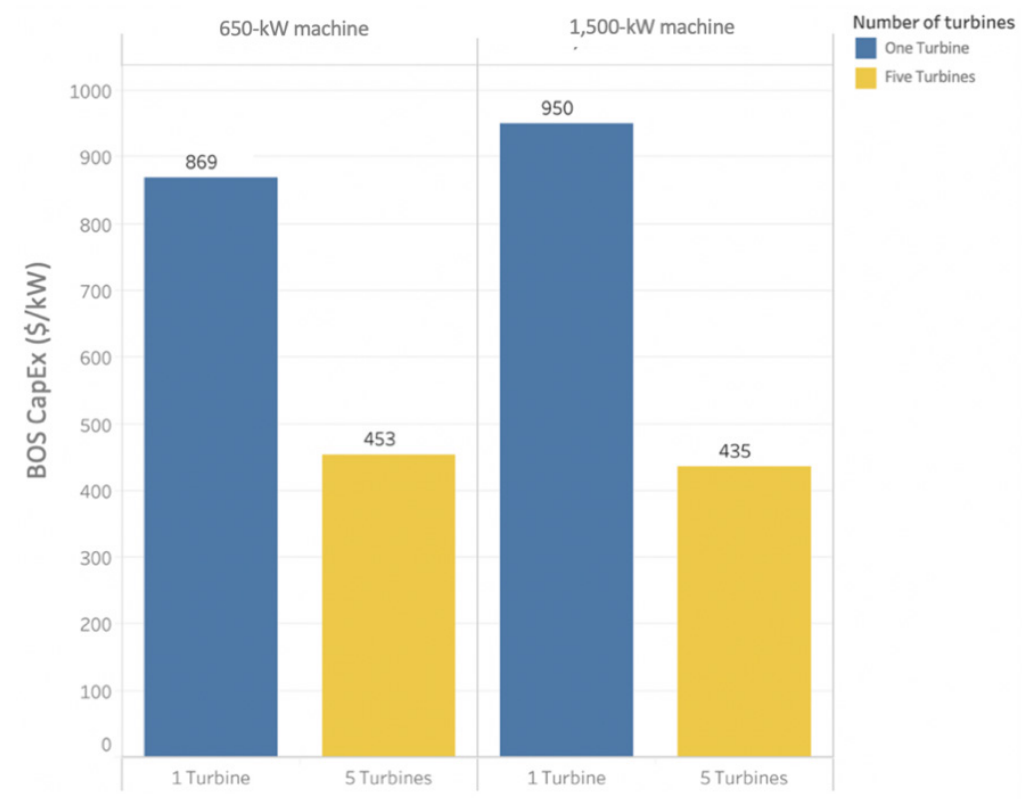

Figure 5. Baseline total project BOS CapEx $(\$ / \mathrm{kW})$ comparison-single-turbine project vs. fiveturbine project (650-kW machine and $1,500-\mathrm{kW}$ machine)

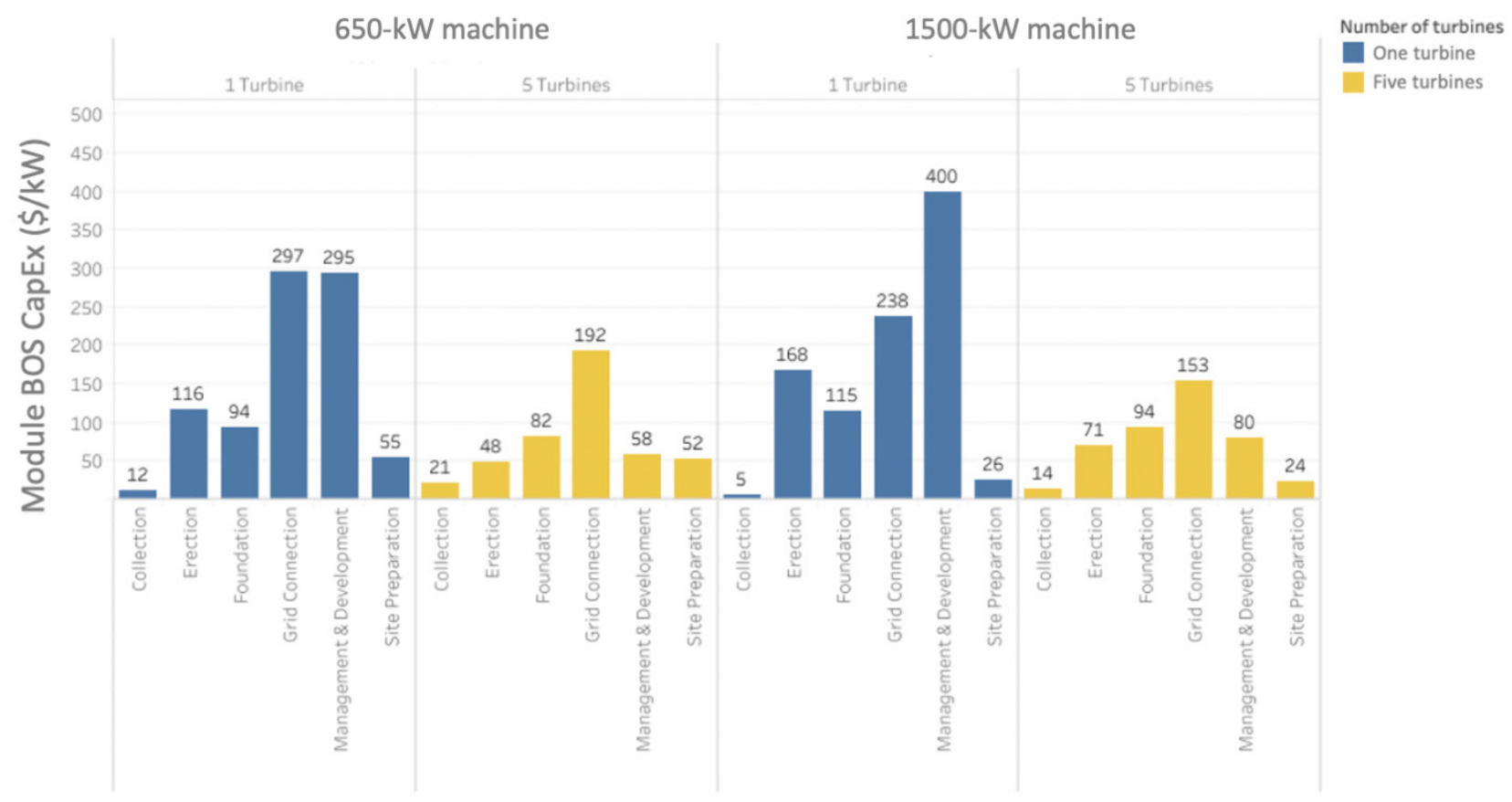

Figure 6. Cost by type for the single-turbine project vs. the five-turbine project $(650-\mathrm{kW}$ machine and 1,500-kW machine)

\subsection{Sensitivity Analysis Methodology}

The BOS cost of a distributed wind project can account for up to $50 \%$ of the project's total capital cost. Reducing total BOS costs of a distributed wind system is thus considered to have a 
significant impact on lowering its overall cost of energy. To start quantifying the potential of BOS cost reductions, we conducted a sensitivity analysis on six BOS cost categories - project management, site preparation, foundation, erection, collection system, and grid connection. To do this, we applied a $1 \%$ cost reduction increment-from zero to $30 \%$ - and estimated the resulting total BOS cost of the distributed wind system. We applied this increment to each of the six discrete cost categories while holding the other five constant. The resulting total BOS cost impact is reported as a percent difference from the baseline scenario. Viewing the results in this format indicates what BOS categories have the highest impact to reduce total BOS costs of the distributed wind system over a variety of turbine and system sizes - as described in Table 3 . The results of the sensitivity analysis are presented in Section 2.5.

\subsection{Sensitivity Analysis Results}

Figure 7 through Figure 12 show the results from the sensitivity analysis. The quantitative impact to each of the distributed wind scenarios is described in Sections 2.5.1 through 2.5.6, with the intention of identifying the categories that have the highest potential impact on total BOS costs and ultimately lower the cost of energy of distributed wind systems.

\subsubsection{Single 20-kW Wind Turbine Results}

As each of the six BOS cost categories are independently reduced from zero to $30 \%$-illustrated in Figure 7-the percent reduction in total BOS for each cost category is quantified on the yaxis. For the single $20-\mathrm{kW}$ (residential) wind turbine scenario, the cost item with the highest impact to total BOS reduction is the management cost, resulting in just over a $13 \%$ reduction in total BOS costs, as shown in Figure 7. The management cost impact is followed by the foundation cost, reducing total BOS cost by about $11 \%$, and then the turbine erection cost, with a reduction of slightly more than $2 \%$. The remaining three cost items (electrical collection, grid connection, and site preparation) have less impact, ranging from approximately $1 \%$ to $2 \%$ reductions. For the case of the $20-\mathrm{kW}$ system, the management cost is assumed to have the largest absolute value than the other cost categories; hence, it has the greatest impact in reducing total BOS costs. Reductions in the number of labor hours and rate spent on project management activities for a residential distributed wind project may greatly reduce the total BOS cost of the project. Further discussion regarding the potential reductions in management costs is discussed in Section 3.1. The reduction of foundation costs through new foundation innovations, such as helical foundations (discussed further in Section 3.4), may also enable significant reduction in total BOS costs for the $20-\mathrm{kW}$ system. 


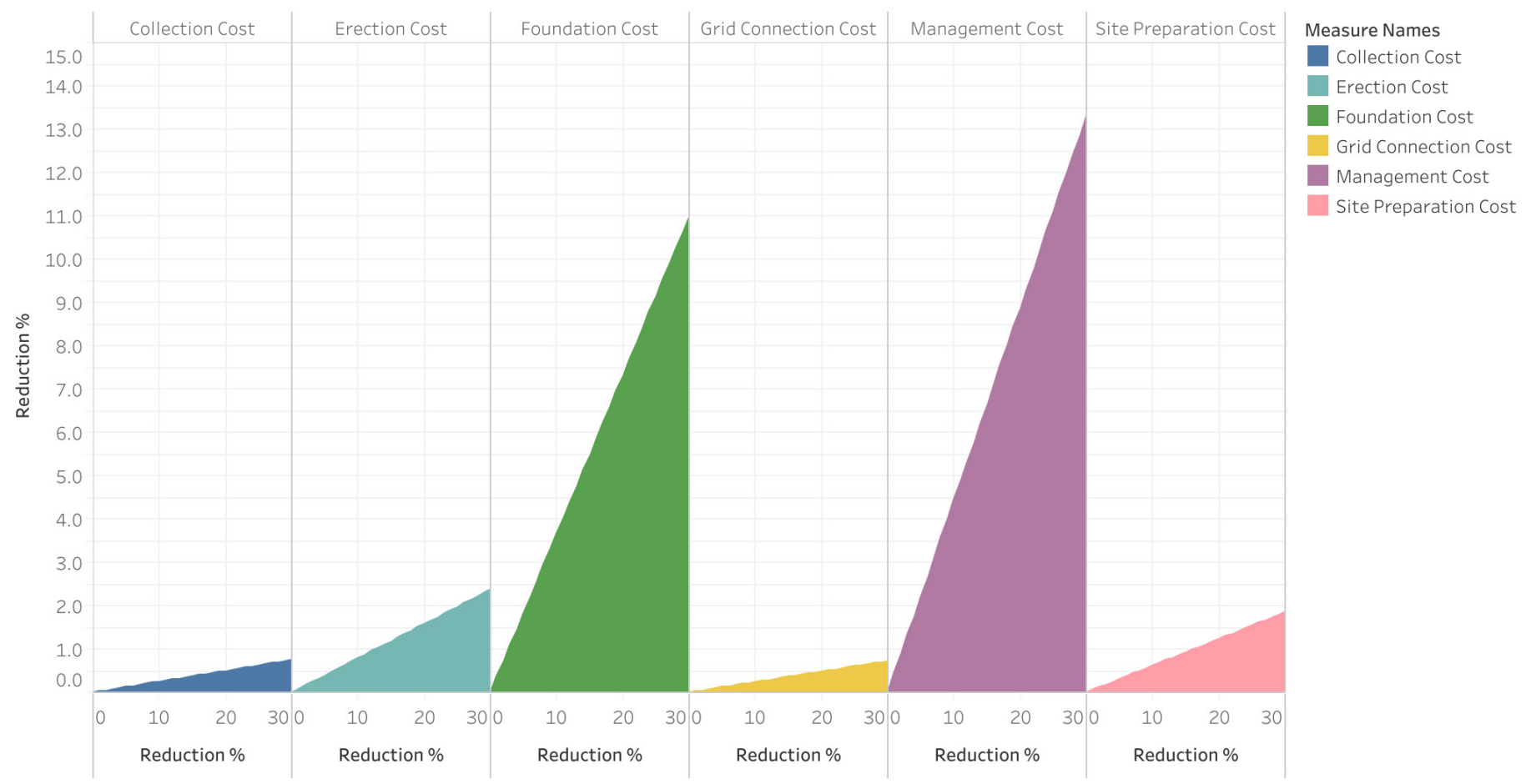

Figure 7. Balance-of-system cost impact for a single 20-kW (residential) wind turbine

\subsubsection{Single 100-kW Wind Turbine Results}

As we step up to the 100-kW (commercial) wind turbine, illustrated in Figure 8, the trends for each of the six cost categories are similar to those for the 20-kW wind turbine (Scenario 1). Total BOS cost reductions are primarily attributed to reductions in management cost, followed by foundation and then erection costs- $13 \%, 11 \%$, and $4 \%$ reduction, respectively. The electrical collection, grid connection, and site preparation have less impact on BOS reductions-less than $1 \%, 1 \%$, and just over $1 \%$, respectively. Analogous to the $20-\mathrm{kW}$ wind turbine (Scenario 1 ), we assumed the management cost to be the greatest absolute cost for the 100-kW system; therefore, it has the largest percent reduction on total BOS costs. Again, the results illustrate the total BOS cost reduction opportunity for innovative foundation technologies that could reduce the cost of the system's foundation. Also, the erection technique and new concepts become more important for consideration with the larger commercial distributed wind system, with increases in total BOS reductions by $2 \%$ compared to the residential wind system. 


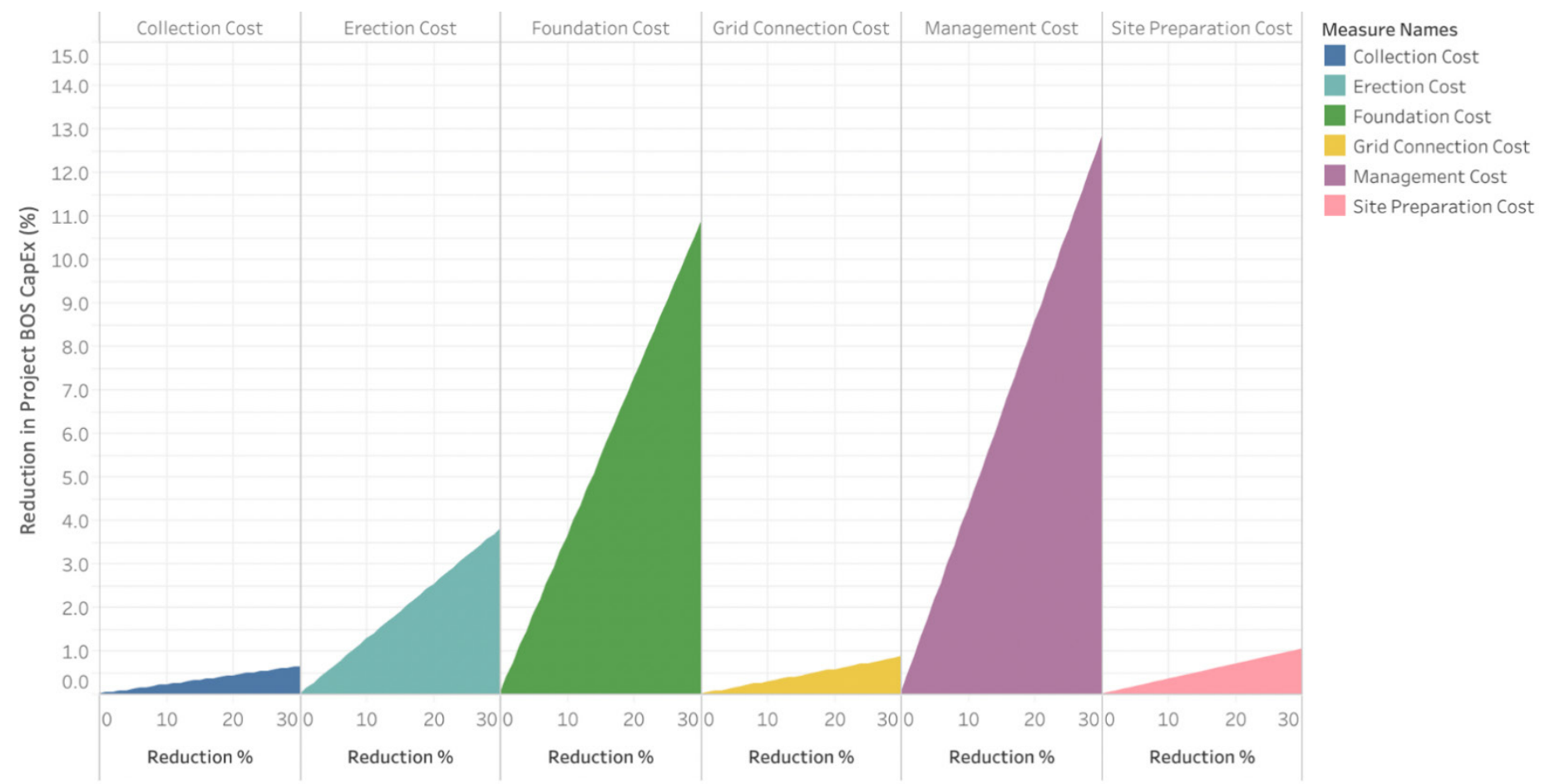

Figure 8. Balance-of-system cost impact for a single 100-kW (commercial) wind turbine

\subsubsection{Single 650-kW Turbine Results}

The analysis results for the $650-\mathrm{kW}$ (midsize) wind turbine (Scenario 3) show a shift in the leading cost reduction category compared to the smaller project sizes. As we continue to scale to this turbine, the prime cost category linked to the highest total BOS cost reduction is the cost for grid connection, which is responsible for a $10.2 \%$ reduction in total BOS cost from the baseline (Figure 9). The next largest cost category accountable for total BOS cost reductions is management and development cost, which reduces total BOS cost by $10.1 \%$. The reduction from the baseline for foundation cost is about $3.5 \%$, and little-to-no BOS cost improvement is observed from electrical collection cost reduction. The shift to the wind turbine erection cost contributing to the third largest reduction in total BOS from the baseline is mainly a result of the high costs associated with the change in type of crane (crawler crane with lattice boom) required for erecting the larger turbine than the crane required for the residential and commercial systems (hydraulic and truck cranes). The erection cost now becomes a significant contributor to BOS cost reduction because the midsize wind turbine requires chartering a large-capacity crane to complete the installation. Additional cost is also accrued for longer road length, wider width, and increased road quality. 


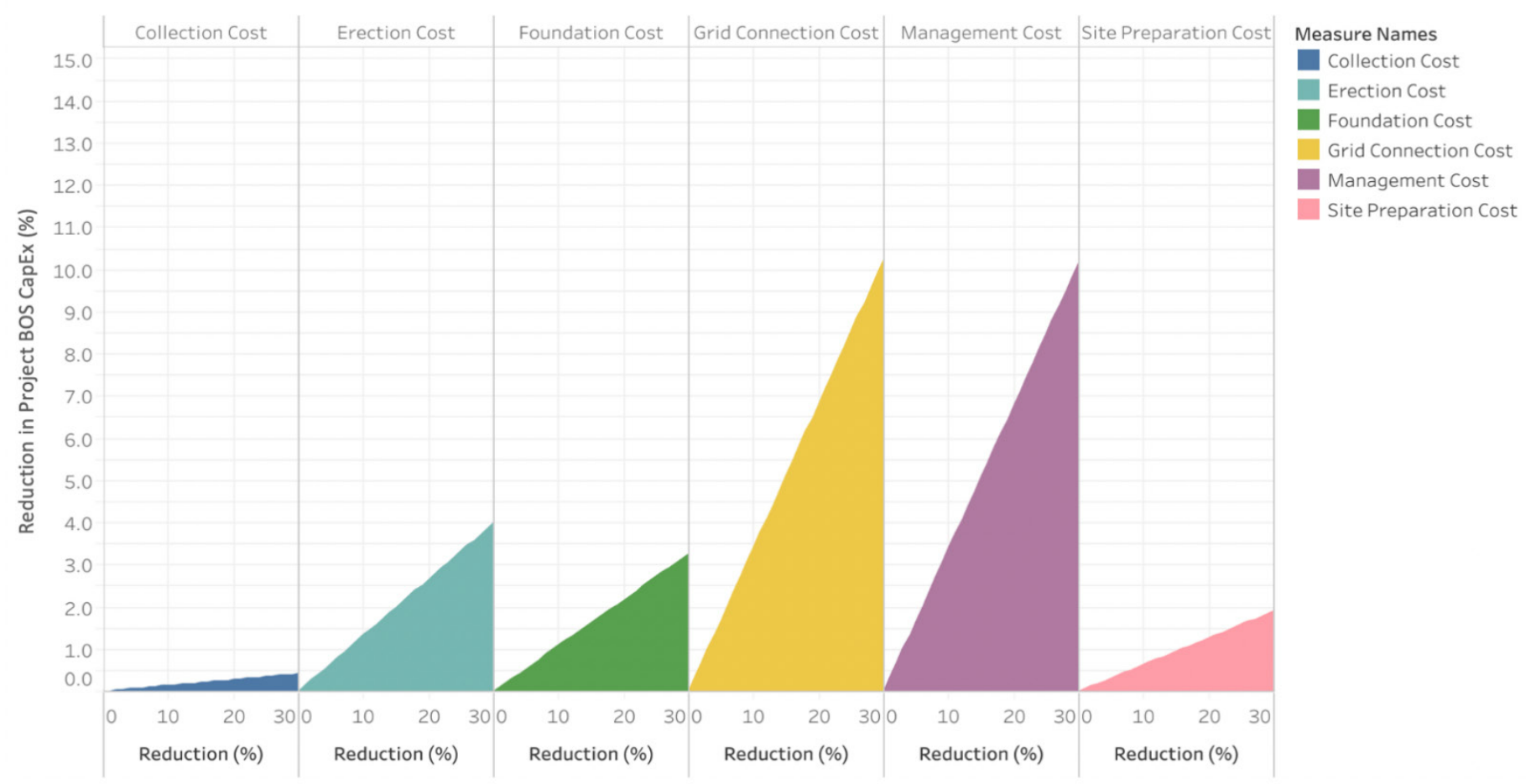

Figure 9. Balance-of-system cost impact for a single 650-kW (midsize) wind turbine

\subsubsection{Single 1,500-kW Turbine Results}

The assessment of the 1,500-kW (large) wind turbine identified the three primary categories accountable for total BOS cost reduction as project management, grid connection, and turbine erection. Figure 10 shows the percent reductions on total BOS cost from project management of $14.5 \%$, with grid connection and turbine erection reduction of project BOS by about $8 \%$ and $5.5 \%$, respectively, assuming a $30 \%$ reduction in each cost category is achieved. The remaining categories - site preparation, foundation, and collection system - show a lesser impact on BOS costs with a $4 \%$ reduction from the turbine foundation and a $1 \%$ reduction from the project's site preparation; the collection system had nearly zero BOS cost reduction. As with the other scenarios with assumed high values of project management cost, we provide an assessment of the potential cost reduction through reduced number of labor hours and lower labor rates in Section 3.1. The grid interconnection costs and turbine erections for the large wind turbine system scenario may also see a reduction from the decreased number of technician hours or hourly rates, and shared mobilization cost of the crane and equipment between the five wind turbines. The qualitative assessment for both these categories is explained in more detail in Section 3.6 and Section 3.2, respectively. 


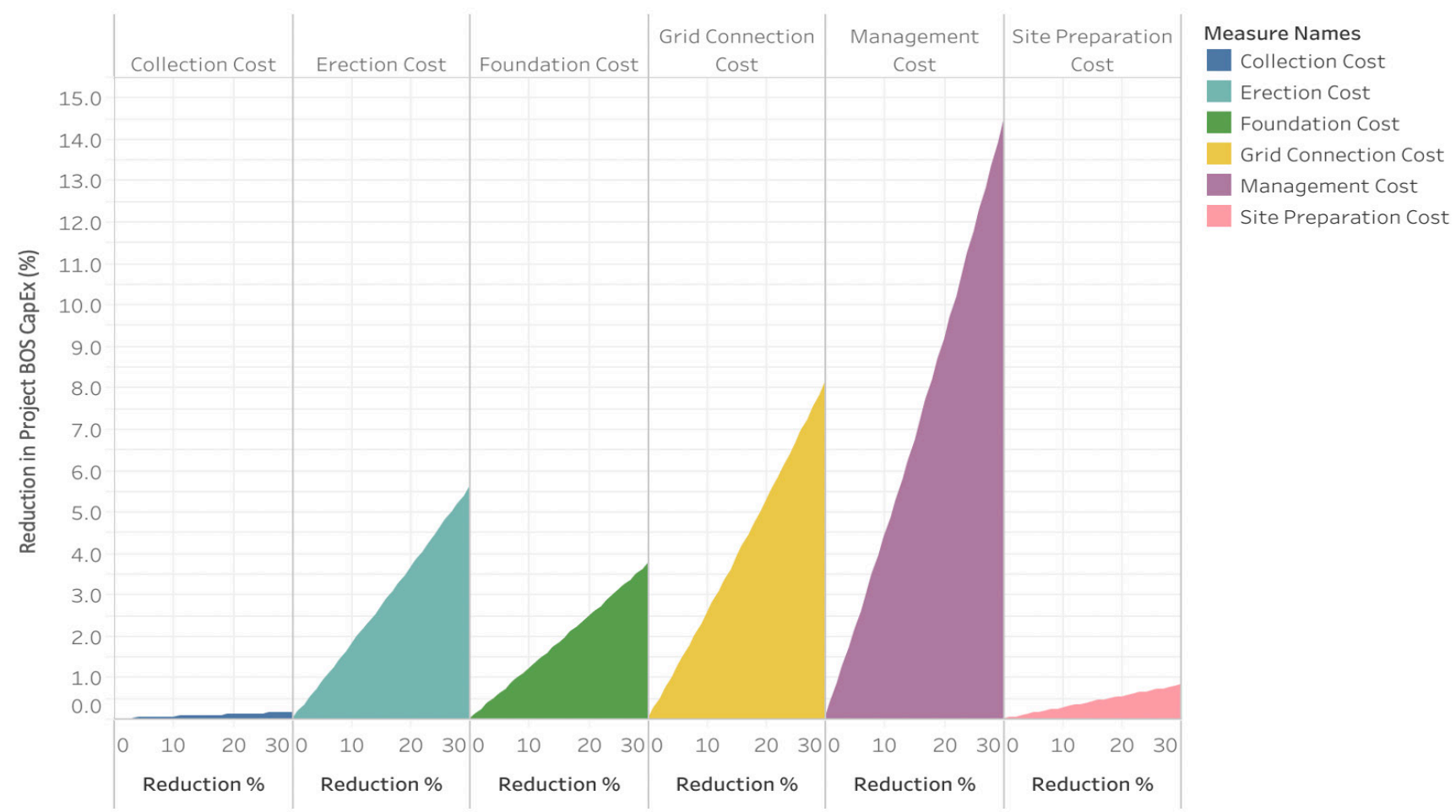

Figure 10. Balance-of-system cost impact for a single 1,500-kW (large) wind turbine

\subsubsection{Results for the Five 650-kW Wind Turbines (3,250-kW System)}

Scenarios 1 through 4 consider a singular wind turbine installation, whereas Scenarios 4 and 5 change the number of turbines installed for each system to five turbines. We consider these five turbine scenarios to not only capture the differences in distributed wind turbine sizes but as areas for additional BOS cost reductions when installing multiple turbines for a single project. At this time, LandBOSSE is limited to assessing these multiturbine installation scenarios for the 650$\mathrm{kW}$ (midsize) wind turbine and the 1,500-kW (large) wind turbine. Adding the capability for LandBOSSE to assess multiturbine installations for the small $(20 \mathrm{~kW})$ and commercial $(100 \mathrm{~kW})$ wind turbines is anticipated to be integrated into future versions of LandBOSSE. Reducing the BOS costs up to $30 \%$ in each of the cost categories for the five midsized wind turbines generally decreases the total BOS cost reductions in each of the six cost categories because efficiencies are gained from distributing the costs over a larger system size. For example, mobilizing a crane to install a single wind turbine is greater than installing five turbines on a cost per unit of power of the system.

Outside of the benefits of distributing the cost amongst a larger system, there are additional BOS cost reduction opportunities for the multiturbine distributed projects. The results of this scenario - shown in Figure 11-report a total BOS cost reduction of about 12.5\%, with a 30\% cost reduction in grid connection cost and a total BOS cost reduction of about $5.5 \%$, with a $30 \%$ reduction in turbine foundation cost. The collection system, management, wind turbine erection, and site preparation costs have a lower impact on BOS cost reduction, ranging from $1 \%$ to $3.5 \%$. When comparing these results to the single midsized turbine installation we see increasesthough in some cases only slight increases-in total BOS reductions for the collection system, 
foundation, and grid connection. However, there is only a decrease in total BOS reduction potential for the management, turbine erection, and site preparation categories.

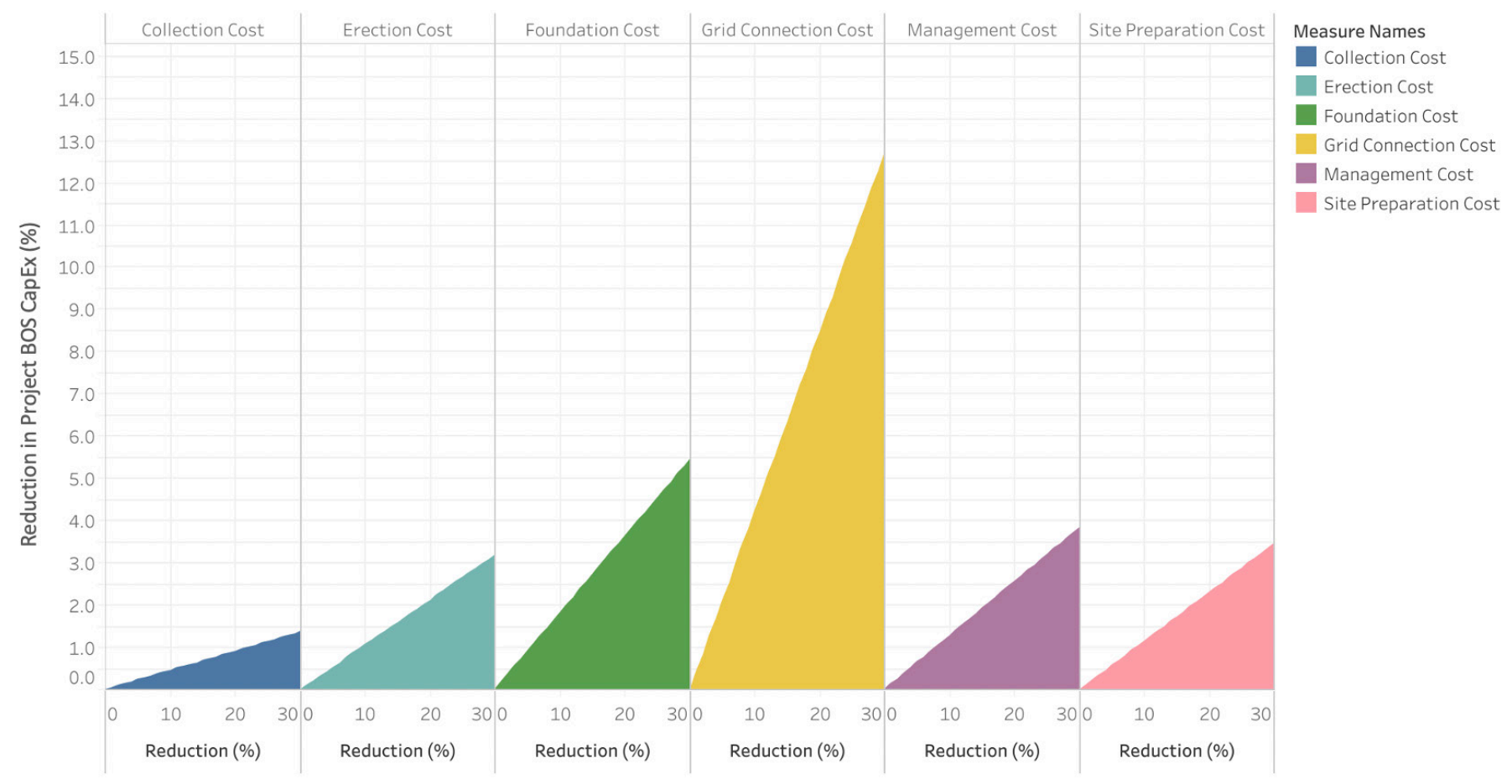

Figure 11. Balance-of-system cost impact for five 650-kW wind turbines

\subsubsection{Results for the Five 1,500-kW Wind Turbines (7,500-kW System)}

In addition to simulating a scenario in which five $650-\mathrm{kW}$ (midsize) wind turbines are installed, we modeled a scenario wherein five $1,500-\mathrm{kW}$ (large) wind turbines are installed. Assuming the same zero-to-30\% cost reduction range within each of the BOS cost categories resulted in the greatest total BOS cost reduction potential attributed by the grid connection cost - $\mathrm{a}$ little over $11 \%$ reduction (Figure 12). Amongst the remaining cost categories-wind turbine erection, foundation, management, and site preparation — we see a similar total BOS reduction between $4 \%$ and $7 \%$, with a nearly negligible impact from the collection system and site preparation costs. When compared to a single large turbine installation scenario, all cost categories, except for grid connection cost (which increases from $8 \%$ to $11 \%$ ), show a declining impact to total BOS costs, with the largest change in the management cost category (going from $14 \%$ to 5.5\%). The reduction in the management cost for the five-turbine scenario is primarily from spreading the management cost over a larger-sized system, hence becoming less of a driver for reducing total BOS cost. With the increased impact of grid connection costs on BOS cost-specific to this scenario - this cost category may benefit from policy-based innovations and detailed mappings of the electric distribution system in the United States, as described in Section 3.6. 


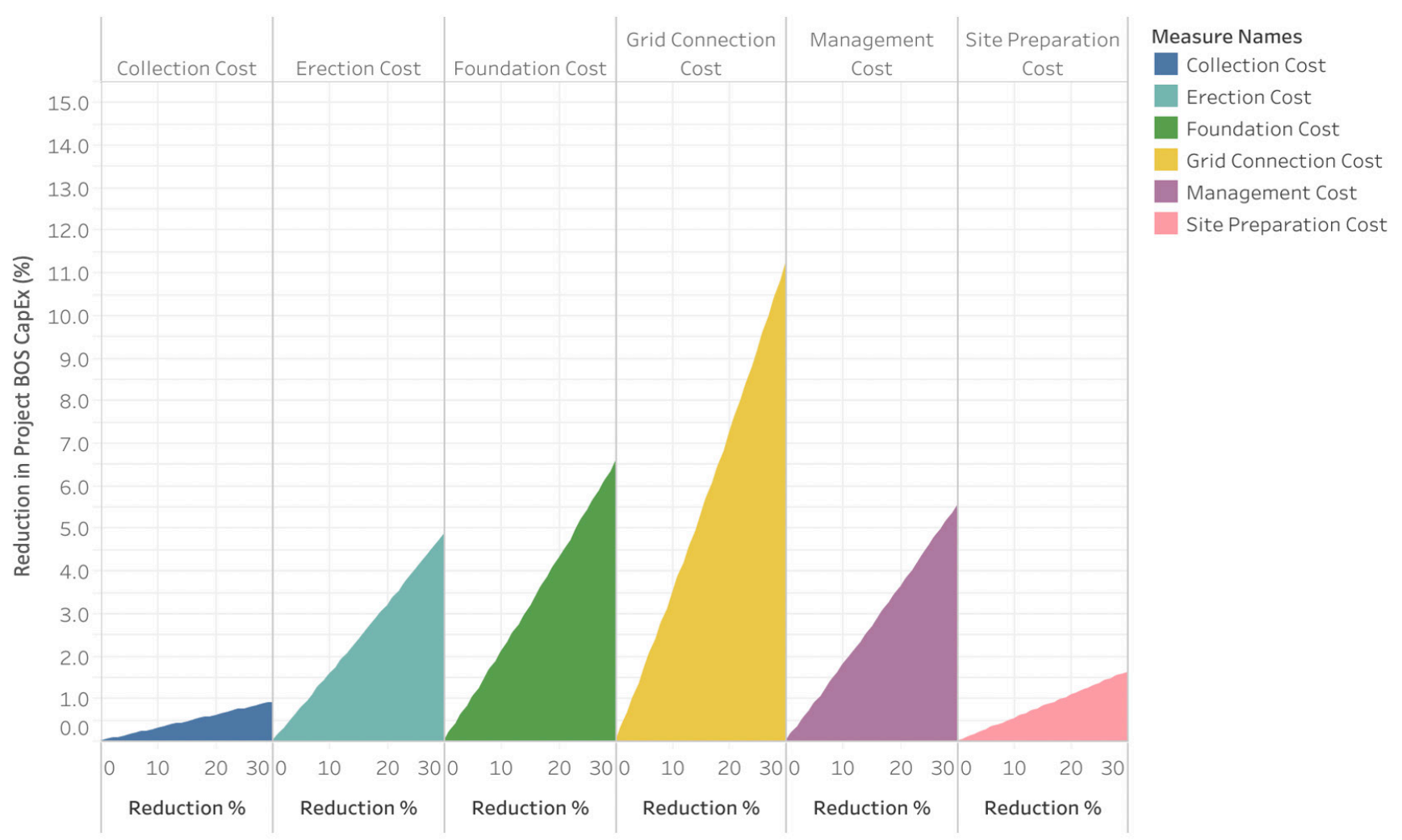

Figure 12. Balance-of-system cost impact for five $1,500-\mathrm{kW}$ wind turbines 


\section{Technology Pathways for Balance-of-System Cost Reductions}

In Section 1, we defined six baseline distributed wind project scenarios ${ }^{3}$ that were simulated in NREL's tool for estimating BOS costs of land-based wind projects - LandBOSSE. In Section 2, we presented the results of the baseline projects, followed by sensitivity analyses on each of the six scenarios to identify BOS cost categories that have the greatest potential in reducing total BOS costs. We achieved this by assuming a 30\% cost reduction in each of the BOS categories and calculating the change in total BOS costs using LandBOSSE.

This section of the report provides more of a qualitative evaluation on technology innovations or pathways that might enable specific cost reductions for distributed wind system BOS costs across the various system sizes. Additionally, analysts estimated the cost reduction of a particular technology innovation or cost reduction pathway on BOS costs in some cases through additional sensitivity analyses. This section is organized by the cost categories used in the sensitivity analysis (i.e., project management/development, site preparation, electrical collection system, wind turbine foundation, wind turbine erection, and grid connection).

We identified the technologies selected for discussion because of their potential to reduce the impact of the key cost drivers identified in Section 2 (Figure 2). This section does not serve to provide an exhaustive discussion of all the technological innovations that currently exist in the distributed wind industry.

\subsection{Project Management and Development}

The project management and development cost category is one of the categories that analysts did not consider any specific innovation to achieve BOS cost reductions. Instead, we considered a hypothetical case in which cost reductions in zoning, permitting, interconnection, and incentives (ZPII) cost within the project management and development category could be realized to estimate a representative savings. ZPII costs comprise fees and labor costs associated with obtaining the appropriate zoning approval, permits, and interconnection agreements and processing the required forms for local, state, and federal incentives (Orrell and Poehlman et al. 2017). As shown in Figure 13, ZPII costs are a sizable portion of the total project BOS CapEx for distributed wind projects using wind turbines in the residential (20-kW-turbine rating), small commercial (100-kW-turbine rating), and midsize ranges (650-kW-turbine rating).

\footnotetext{
${ }^{3}$ The first four scenarios include single-turbine distributed wind projects in the following project scales: residential, commercial, midsize, and large. And the final two scenarios include five-turbine projects using midsize and largescale turbines.
} 


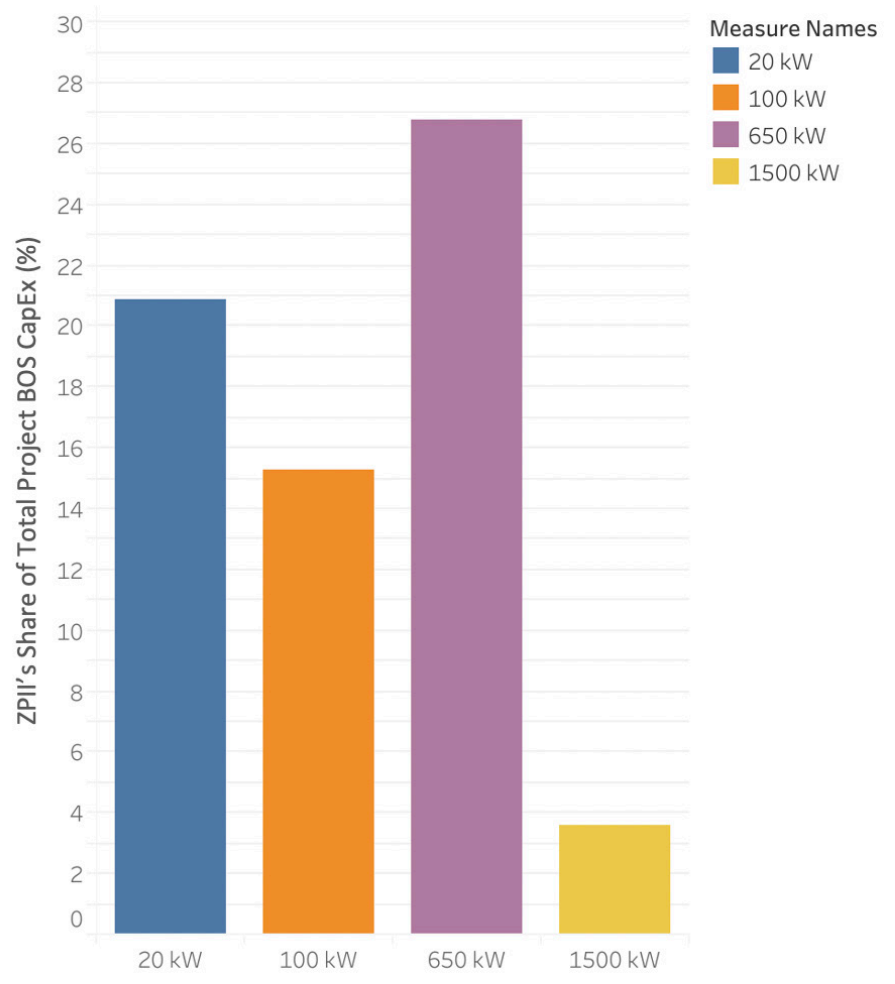

Figure 13. ZPII's share of total project BOS CapEx (\%) (single-turbine projects)

Using proprietary data obtained from industry for actual distributed wind projects currently deployed in the United States, we analyzed cost reduction opportunities in ZPII costs. ${ }^{4}$ These data were broken down by component-level costs (application fee and/or processing costs) pertaining to zoning, electrical, environmental, building, Federal Aviation Administration, erosion and sediment, incentives, and miscellaneous (items that did not fit within the other categories). Figure 14 shows the average number of days taken for processing all permits and applications within the ZPII cost category, for various wind turbine size ranges, and Figure 15 shows the average daily cost (\$/day) of ZPII-related activities for various wind turbine size ranges.

\footnotetext{
${ }^{4}$ Although insightful, the sample size of this database was limited. The database used for analyzing ZPII costs comprised 13 residential-scale projects, 11 commercial-scale projects, 3 midsize-scale projects, and 3 large-scale projects.
} 


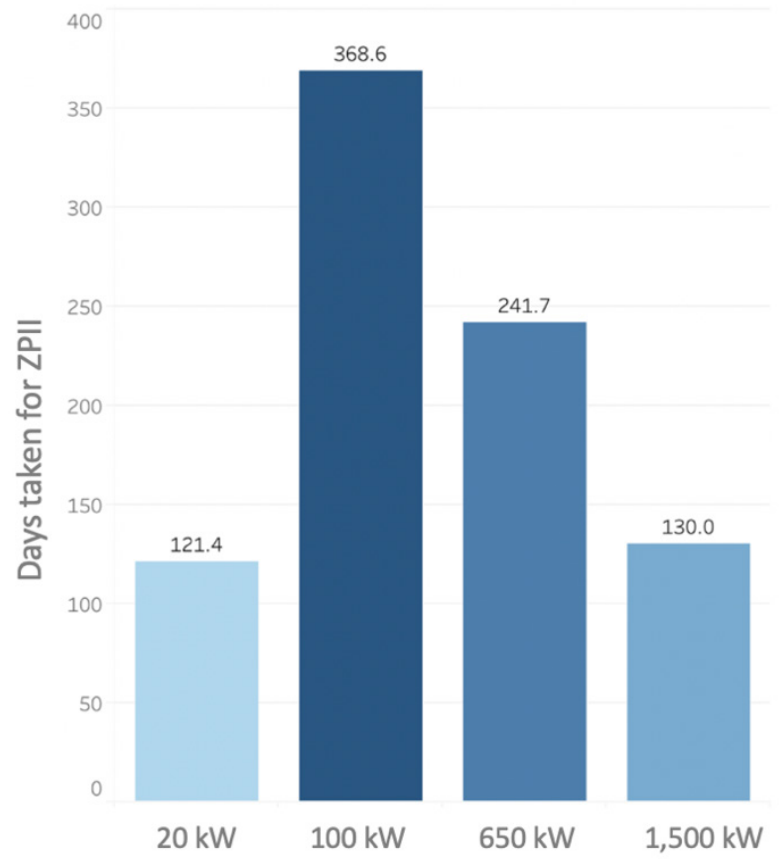

Figure 14. Total number of days (average) taken to complete applications for ZPII at each project size (single-turbine projects)

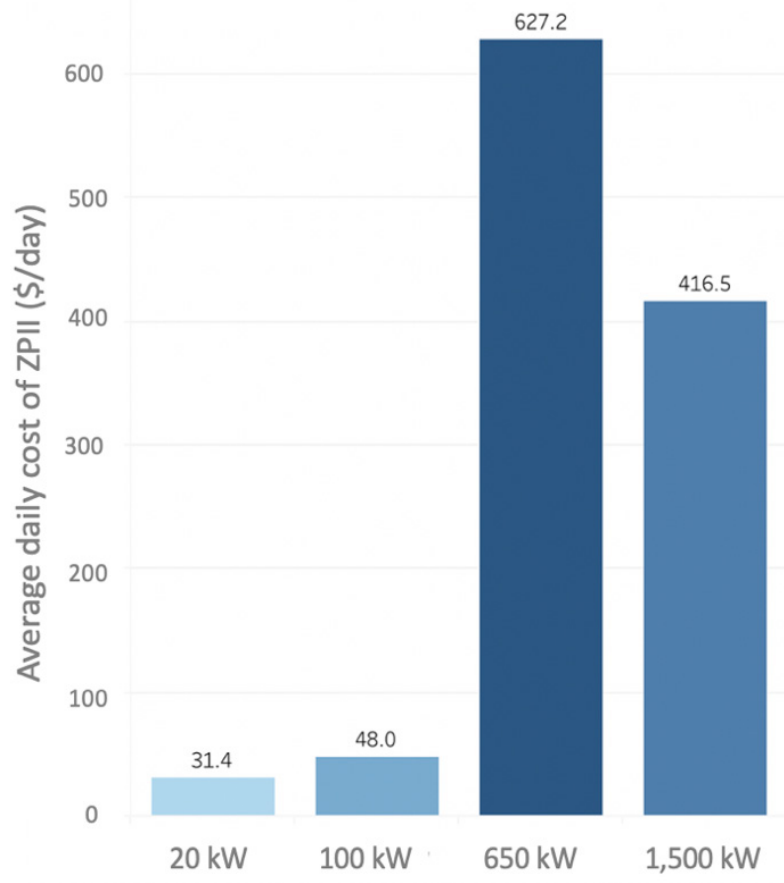

Figure 15. Average cost per day of ZPII application timeline at each project size (single-turbine projects) 
It is interesting to note that the average ZPII processing times were quite similar for the residential- and large-scale turbine sizes. Large, utility-scale wind turbines have more sophisticated performance standards and design specifications that result in shorter ZPII application processing times. However, a plausible explanation for the relatively low processing time for residential-scale projects is that the counties in which these reported projects are located currently have an existing standardized framework for processing ZPII-related applications. Residential-scale projects applying in counties with no such existing ZPII-related application processing frameworks in place could easily take much longer or get rejected. ${ }^{5}$

Within the ZPII cost category, utility interconnection cost is one of the biggest cost drivers; in some cases, accounting for up to $89 \%$ of the total ZPII cost of a project (based on data collected from industry). Accordingly, in assessing the biggest drivers of ZPII costs, we plotted utility interconnection cost (which is rolled into the ZPII cost category) as a function of the number of days it took to process and approve an application. As shown in Figure 16, there is a sudden rapid increase in the cost of utility interconnection once the number of days taken to process a project's application crosses $100 .^{6}$

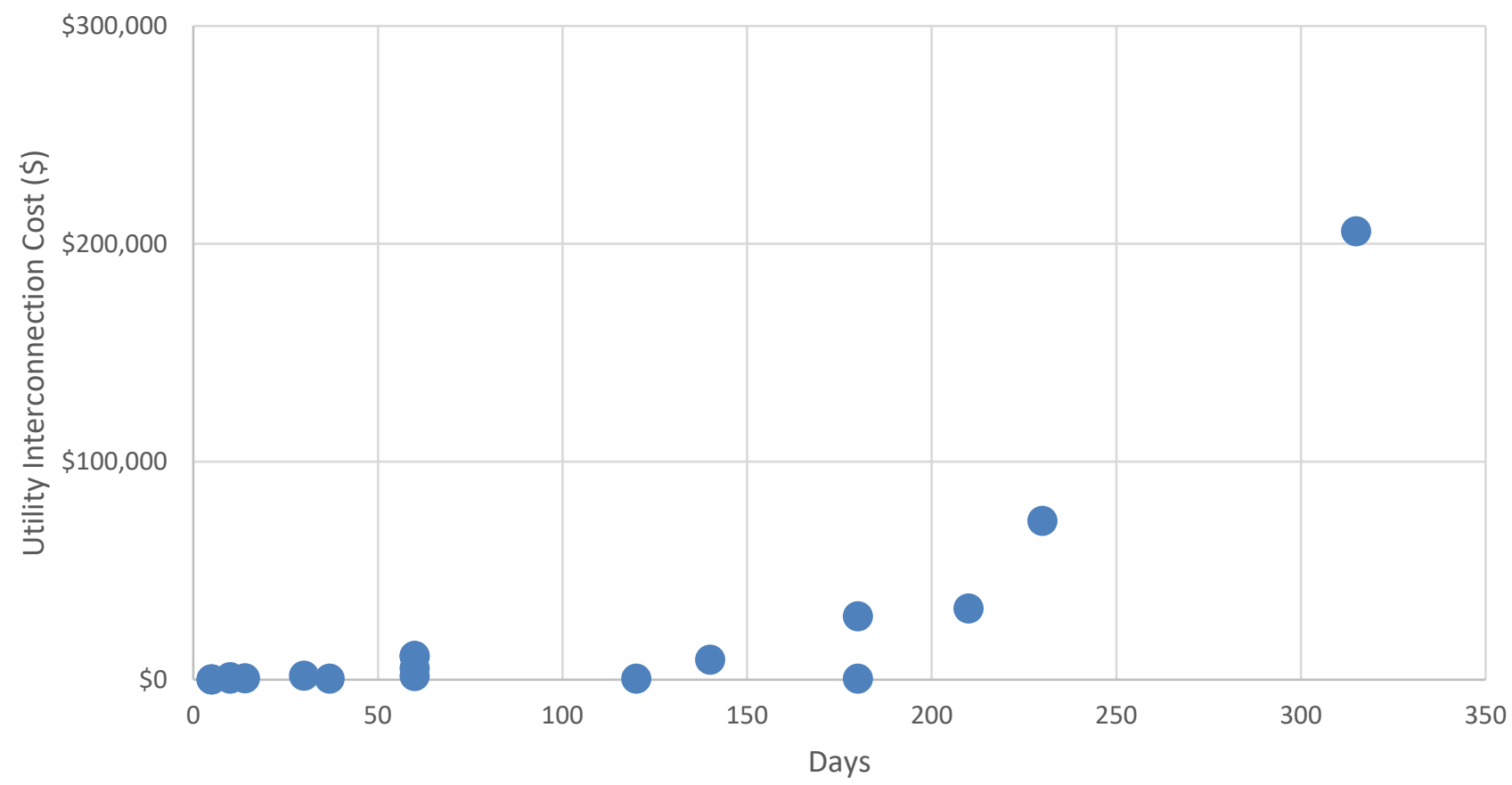

Figure 16. Utility interconnection cost vs. number of days taken for processing a project's interconnection request

\footnotetext{
${ }^{5}$ U.S. counties with no current application framework in place for distributed wind projects may also have a height restriction for residential structures that applies to wind turbines as well. This height restriction tends to be of the order of $35 \mathrm{ft}$ in residential zones. Therefore, wind turbines with a hub height greater than $35 \mathrm{ft}$ in such counties would require a special use permit or variance, which leads to scrapping the project or inflating the cost of permitting.

${ }^{6}$ Although insightful, the sample size of this database was limited and comprised of 13 residential-scale projects, 11 commercial-scale projects, 3 midsize-scale projects, and 3 large-scale projects.
} 
Figure 17 and Figure 18 illustrate the impact on total ZPII cost over a range of reductions in application process times. A $0 \%$ reduction in ZPII-related application processing times represents the base-case (actual) average ZPII cost, whereas a reduction of percent (10-50) in processing times represents the new expected average ZPII cost (in \$).

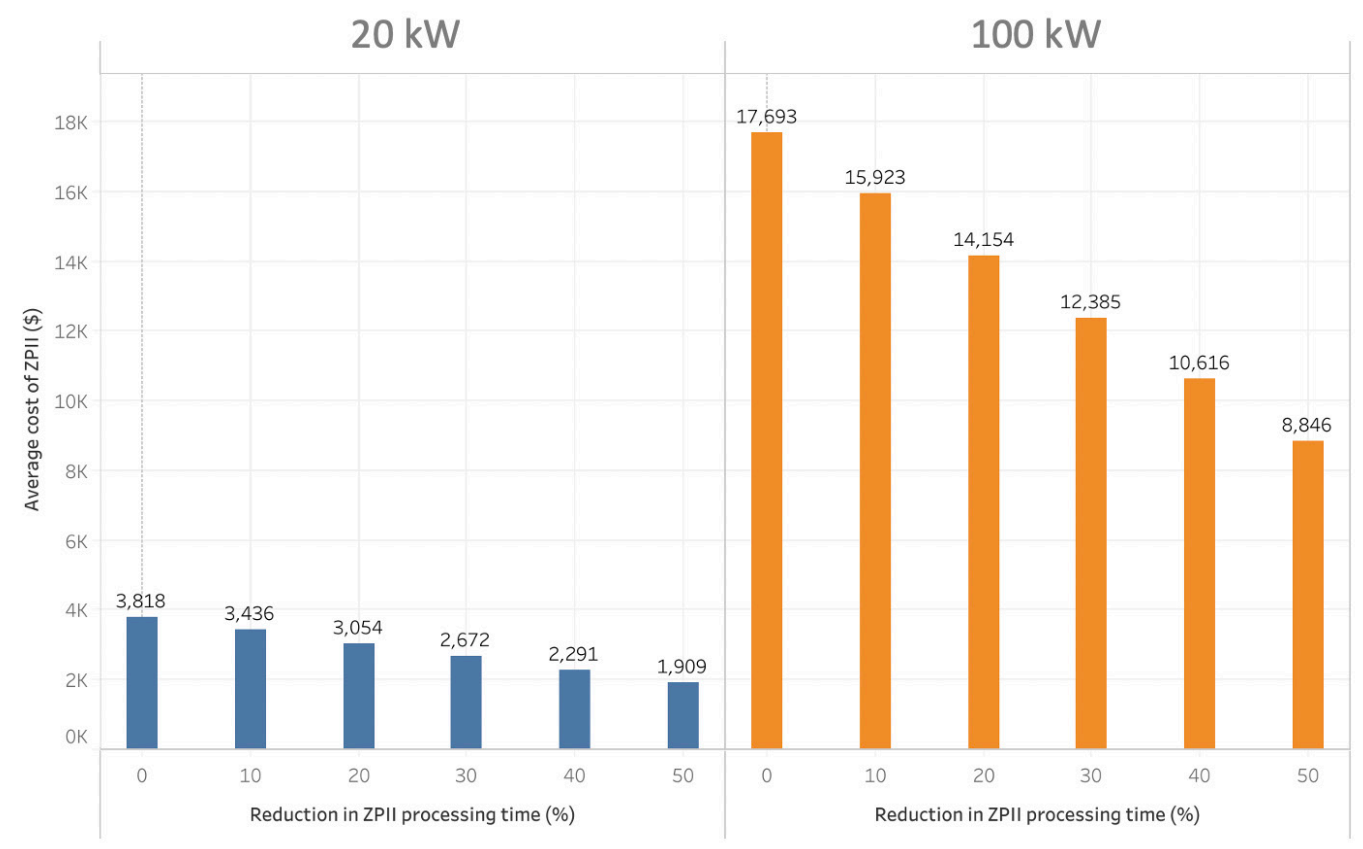

Figure 17. Impact on total ZPII cost resulting from a reduction in processing time (single residential and commercial-scale wind turbine projects)

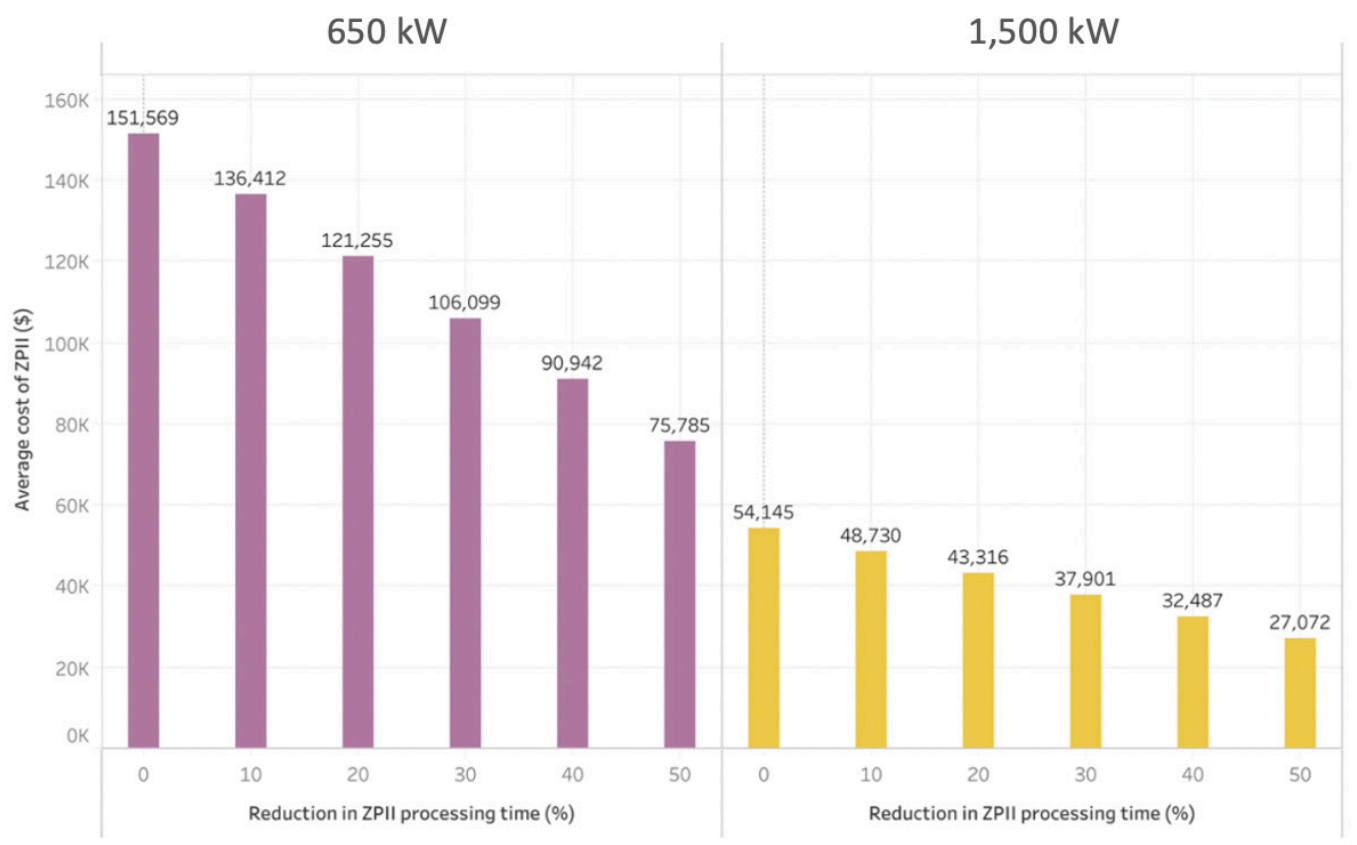

Figure 18. Impact on total ZPII cost resulting from a reduction in processing time (single midsize and large-scale wind turbine projects) 
Figure 19 shows the percentage reduction of total project BOS CapEx for single-turbine projects (20-, 100-, 650-, and 1,500-kW turbine ratings), caused by hypothetical reductions in ZPIIrelated application processing times to half of the current average processing times (given the assumption that total cost of the ZPII cost category is directly related to days taken for processing ZPII applications). These hypothetical reductions in processing times could potentially be realized through more standardized application and processing frameworks across all states and counties in the United States, and for all wind turbine sizes (residential, commercial, midsize, and large [utility-scale] machines).

Based on commentary from industry stakeholders, there also appears to be a standard of care demarcation based on project size, largely resulting from requirements from third-party financing, which affects BOS and ZPII costs. Many smaller distributed generation projects rely entirely on owner cash or owner balance sheet financing. Larger distributed generation projects (involving megawatt-scale machines) begin to rely on more traditional sources of project finance including institutional lenders and nonrecourse debt and equity. These sources of institutional capital typically require a higher level of due diligence and independent oversight in a project that can add substantially to project costs. For example, typical institutional financiers require a year-long wind resource assessment and an independent wind resource assessment or audit. This cost alone can exceed $\$ 100,000$. In addition, the legal and transactional expenses for financing these deals can exceed $\$ 400,000$ for a transaction. Finally, projects that are of sufficient scale to use tax equity structures have substantial costs associated with securing this financing.

Notably, a study carried out by Sunrun and reported to the U.S. Department of Energy looked at the impact of local permitting on the cost of residential-scale solar power (Sunrun 2010). They reported that streamlining and standardizing the local permitting process for residential solar would be equivalent to a solar subsidy of $\$ 1$ billion over the next 5 years. They reported that a lack of a streamlined permitting procedure inflated the cost of solar by $\$ 400 / \mathrm{kW}$ (Wesoff 2011). 


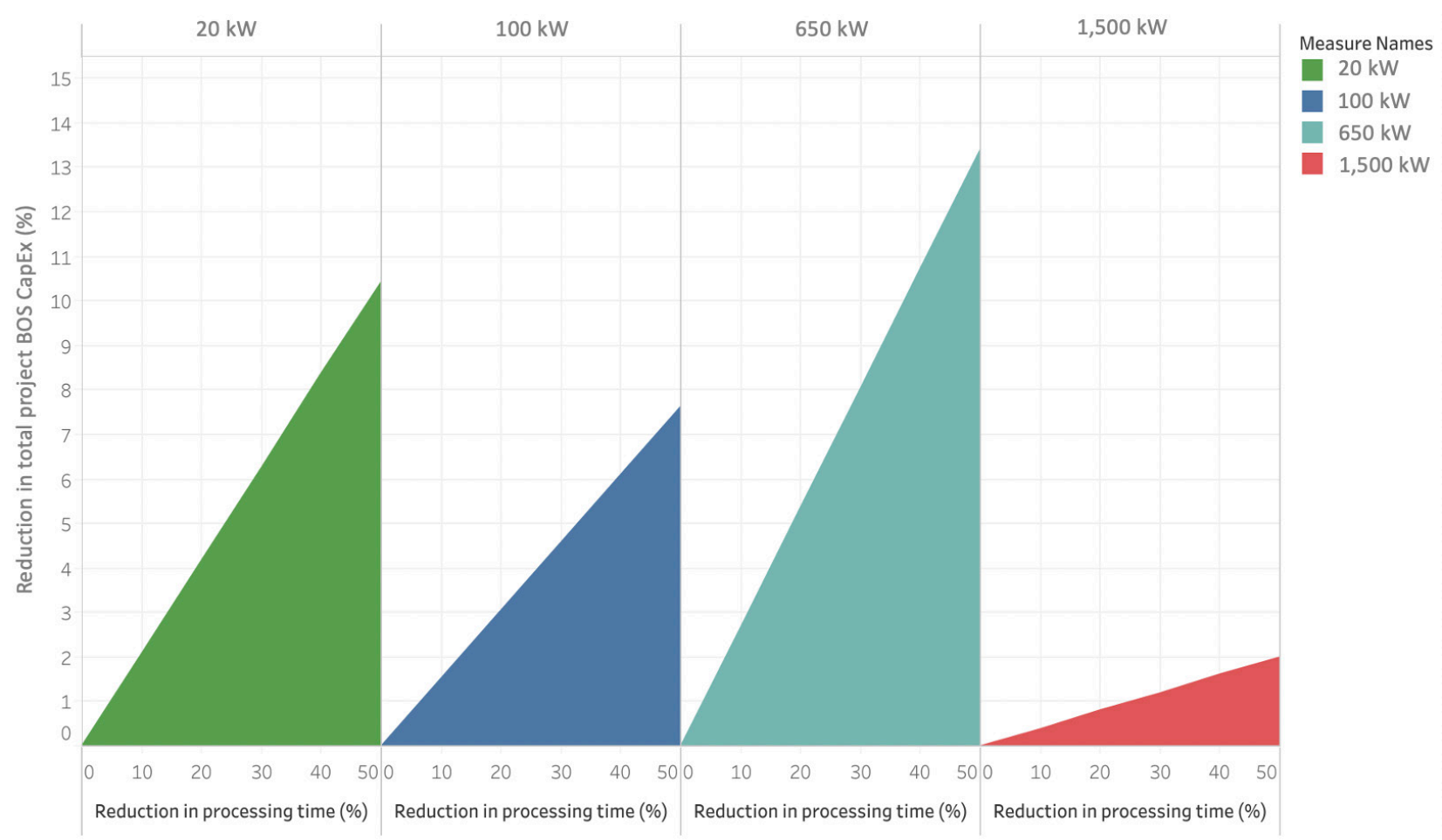

Figure 19. Impact on total project BOS CapEx from reducing ZPII processing time to $50 \%$ of the current average processing time (single-turbine projects) ${ }^{7}$

\subsection{Site Preparation}

Site preparation does not have a directly associated innovation considered in this assessment. As described in Section 2.2.2, LandBOSSE calculates the cost of roads construction and site preparation around every wind turbine in a project. The area (in square meters $\left[\mathrm{m}^{2}\right]$ ) for site preparation specified in LandBOSSE's inputs (per turbine) was set equal to the swept area of the rotor. Site preparation activities at the base of the tower primarily involve assembling the rotor, offloading turbine components, installing crane pads, and assembling the crane for wind turbine erection and installation. The total area required for site preparation at the base of each turbine tower is primarily driven by the total area needed for assembling the crane (specified in a crane's technical manual). Additionally, high-quality roads are needed to be able to mobilize the cranes to and from the project site. Consequently, larger cranes will require wider paved roads, and a larger land footprint at the base of each wind turbine for crane assembly.

Therefore, an indirect reduction of a project's site preparation cost is possible for the mid and large-size wind turbine projects because of innovations that promise alternative erection strategies-like self-climbing cranes (Section 3.5). Self-climbing cranes can bring down site preparation costs because projects would no longer require large land footprints to assemble the smaller cranes (which promise minimal assembly requirements), and no longer require the type of roads needed to transport the crane to and from the project location (because of the

\footnotetext{
${ }^{7}$ The ZPII cost is highly dependent on the actual project, its location, the customer, and the local policies. Analysts worked with limited data when analyzing the cost relationships in this section.
} 
containerized solutions for mobilizing smaller cranes). For the commercial- and residential-scale wind turbines, site preparation costs make up a smaller portion of the project BOS CapEx because of a smaller land footprint (smaller rotor diameters) and construction of lower-quality, dirt roads.

Refer to Section 2 for a high-level sensitivity analysis on the impact of site preparation cost on total project BOS CapEx, which has the potential to be realized for projects that do not require mobilization of large cranes on-site.

\subsection{Electrical Collection System}

As described in Section 2, the electrical collection system cost of a project is the cost of cabling (trenching and laying medium-voltage AC cables underground). The electrical collection system tends to be the lowest cost category across all scenarios described in the sensitivity analysis in Section 2.1 and illustrated in Figure 7 through Figure 12. In all six scenarios, defined in Table 3, a $30 \%$ cost reduction in the electrical collection system - from the baseline-resulted in less than a $1 \%$ reduction in total BOS costs. This result, in and of itself, is a valuable outcome because it stresses that even a high reduction in collection system costs only has a minor impact total BOS cost reduction. To this point, cost reduction efforts may be better spent in the other BOS cost categories that have a larger impact on reducing BOS costs.

\subsection{Wind Turbine Foundation}

The baseline wind turbine foundation type considered in Section 2.2.3 was the spread-foot, reinforced concrete foundation (Eberle et al. 2019). This gravity-based foundation is one of the most common in the market. However, as discussed in Section 2.3, foundation cost is one of the bigger costs across all turbine sizes, which is a result of the highly material- and labor-intensive nature of this spread-foot foundation type. Accordingly, the alternative foundation technologies explored are the piled and AirBASE foundation types, both of which potentially require less concrete.

The piled foundation type we explored for the residential-scale wind turbine size $(20 \mathrm{~kW})$ is helical anchors. Helical anchors comprise helical bearing plates welded to a central steel shaft that is driven into the ground using an earth anchor driver, and the turbine loads are transferred to the soil through the helical bearing plates, as illustrated in Figure 20. Helical-anchored foundations for smaller wind turbine installations replace the need for reinforced concrete, resulting in a considerable drop in the foundation cost component of the total project BOS cost. Helical-anchored foundations, however, currently do not work for wind turbine sizes greater than $20 \mathrm{~kW}$, because these larger turbines require a deadweight to balance their loads. 


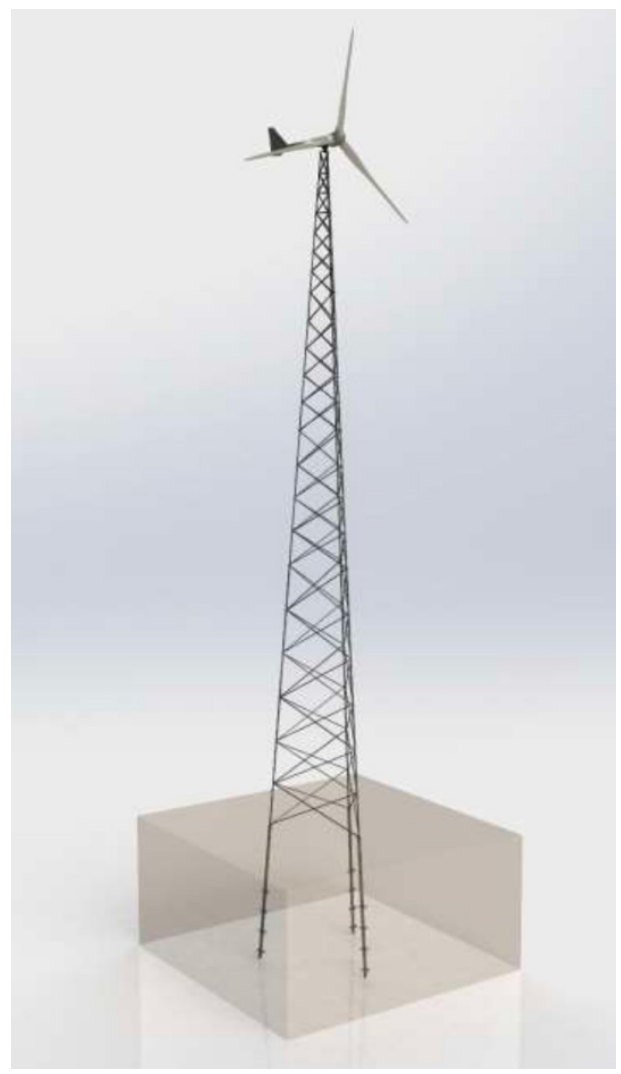

Figure 20. Rendition of the Bergey 15-kW wind turbine with a helical-anchored foundation. Image from Bergey (2018)

From recent cost estimates provided by distributed wind industry stakeholders, a helicalanchored foundation type is estimated to reduce foundation costs by up to $70 \%$ relative to the spread-foot reinforced concrete foundation, equating to a potential drop in foundation cost from $\$ 1,135 / \mathrm{kW}$ to $\$ 340 / \mathrm{kW}$. This potential reduction in foundation cost was estimated assuming a three-legged, 100-foot-tall lattice tower supporting a residential-scale wind turbine, with each leg bolted to a 20-foot-deep helical anchor. No reinforced concrete was required for this tower and foundation type, which is the primary driver for the steep drop observed in the foundation cost bucket of the $20-\mathrm{kW}$ project as a result of the labor and material intensive nature of reinforced concrete foundations.

As discussed in Section 2, foundation is the second-highest cost bucket identified in the 100-kW wind turbine project, representing roughly $\sim 36 \%$ of the total project cost (shallow, spread-foot, reinforced concrete foundation type). This is because of the highly material- and labor- intensive process of constructing the shallow, reinforced concrete foundation. Accordingly, the cost of materials represents $43 \%$ of the total foundation cost, and labor represent $25 \%$. Preliminary discussions with industry partners revealed that prefabricated deep foundations - particularly, prefabricated concrete pier foundations and steel monopile foundations - for commercial-scale wind turbines may have the potential for considerable cost savings. Deep foundations tend to be less material-intensive, resulting in material cost savings. They also have the potential to achieve labor cost savings by minimizing on-site labor and eliminating curing time required by typical 
spread-foot, reinforced concrete foundation types. Modularity of deep foundations will further enable logistics cost savings and is thus a promising area for future research and development.

We did not explore deep foundation types as potential foundation cost reduction opportunities for the mid and large-size wind turbines mainly because the deep foundation design is highly dependent on the site's soil-bearing pressure. For larger wind turbine sizes, piled foundations require a pile cap (steel-reinforced concrete) to serve as a dead weight to balance out the larger turbine loads. Generally, the volume of concrete used in pile caps is smaller than the volume of concrete used in a shallow, spread-foot foundation. However, the volume of reinforced concrete used in pile caps varies depending on the soil-bearing pressure, among other project-specific wind turbine loads.

In general, as shown in Figure 21, deep foundations are typically used for larger wind turbines in sites with low soil-bearing pressure, whereas shallow, spread-foot foundations are preferred for sites with high soil-bearing pressure. As a general rule of thumb, all things constant, deep foundation types can cost between 1.5 and 2.5 times more than a standard shallow, spread-foot foundation. The higher cost associated with the deep foundation type for mid and large-size wind turbines is a result of the added cost of (1) renting and mobilizing additional equipment on-site, such as a pile driver, for digging holes in the earth, (2) assembling rebar cages that are lowered into the hole, (3) injecting concrete into these foundation holes, and (4) including additional wait time until the concrete in the in-situ piles cures (roughly an additional week of wait time). These steps are in addition to the steps required for constructing the reinforced concrete pile caps, which follow a similar construction process as that of the shallow, spread-foot foundation considered in LandBOSSE (Eberle et al. 2019).

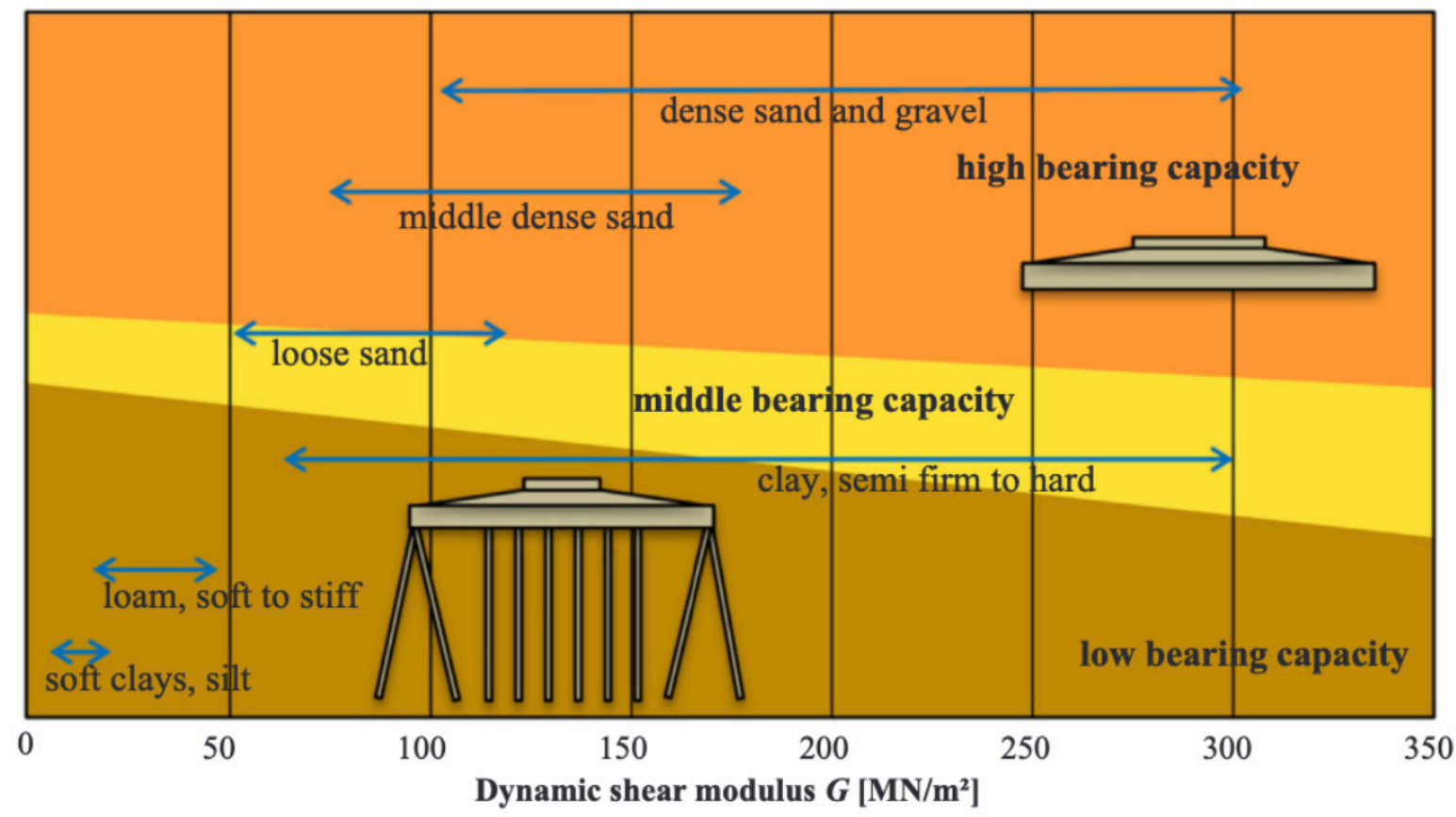

Figure 21. Wind turbine foundations on different soils; divided into three main load bearing classes. Image from Michel et al. (2018) 
Therefore, the technologies we explored for midsize wind turbines and up were limited to innovations within the shallow, spread-foot foundation technology type, and were focused on innovations that lower the amount of material and labor required per foundation. One specific alternative foundation technology we explored for larger turbines (mid and large sizes) was the AirBASE. Patented in 2018, this technology carried out its feasibility for wind turbines in the range of 2-5 MW, and for tower heights in the range of 90-160 meters. ${ }^{8}$ As opposed to the idealized cylindrical spread-foot foundation currently considered in LandBOSSE, AirBASE technology comprises a precast, cross-shaped transition piece (made up of two precast girders) connected to four isolated supports on both ends of the girders (see Figure 22). As a result of this design, there is a reduction in the amount of concrete required per wind turbine foundation. The girders are precast prior to arrival on-site, thereby reducing the labor hours required per wind turbine. The four isolated supports, which are made of reinforced concrete, are soil-dependent and constructed on-site.

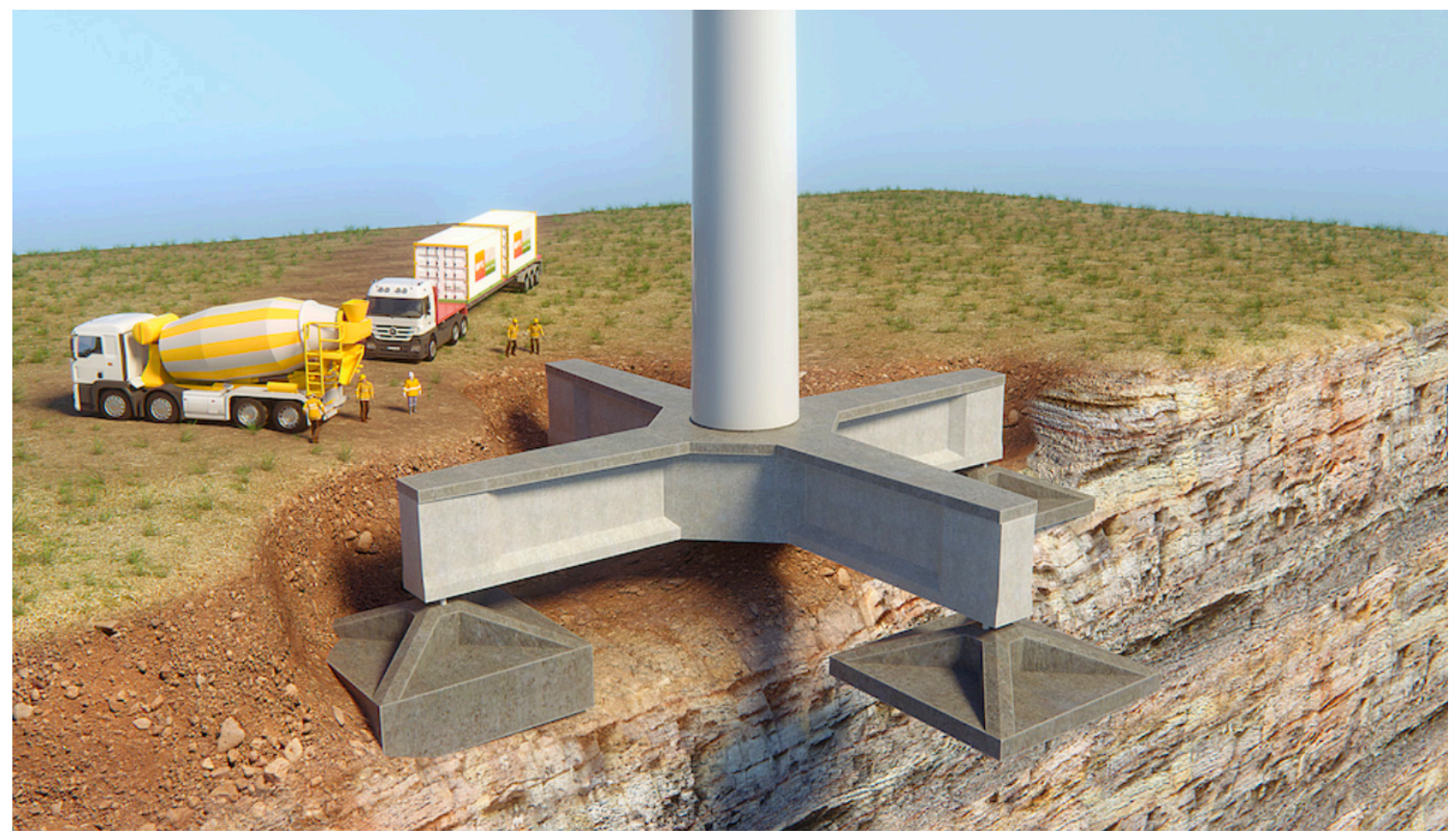

Figure 22. Rendition of the AirBASE foundation design that uses less concrete than the traditional shallow, spread-foot, reinforced concrete foundation. Image from HWS Concrete Towers (undated)

As shown in Figure 23, the AirBASE technology claims to reduce the concrete volume used in foundations by up to $35 \%$, which, if realized, translates to a reduction in total cost of foundation of up to $30 \%$ (HWS Concrete Towers undated).

\footnotetext{
${ }^{8}$ NREL did not participate in independently validating the technoeconomic viability and benefits promised by this technology. The main focus here is to highlight the magnitude of the benefits that may be realized from these types of foundations.
} 


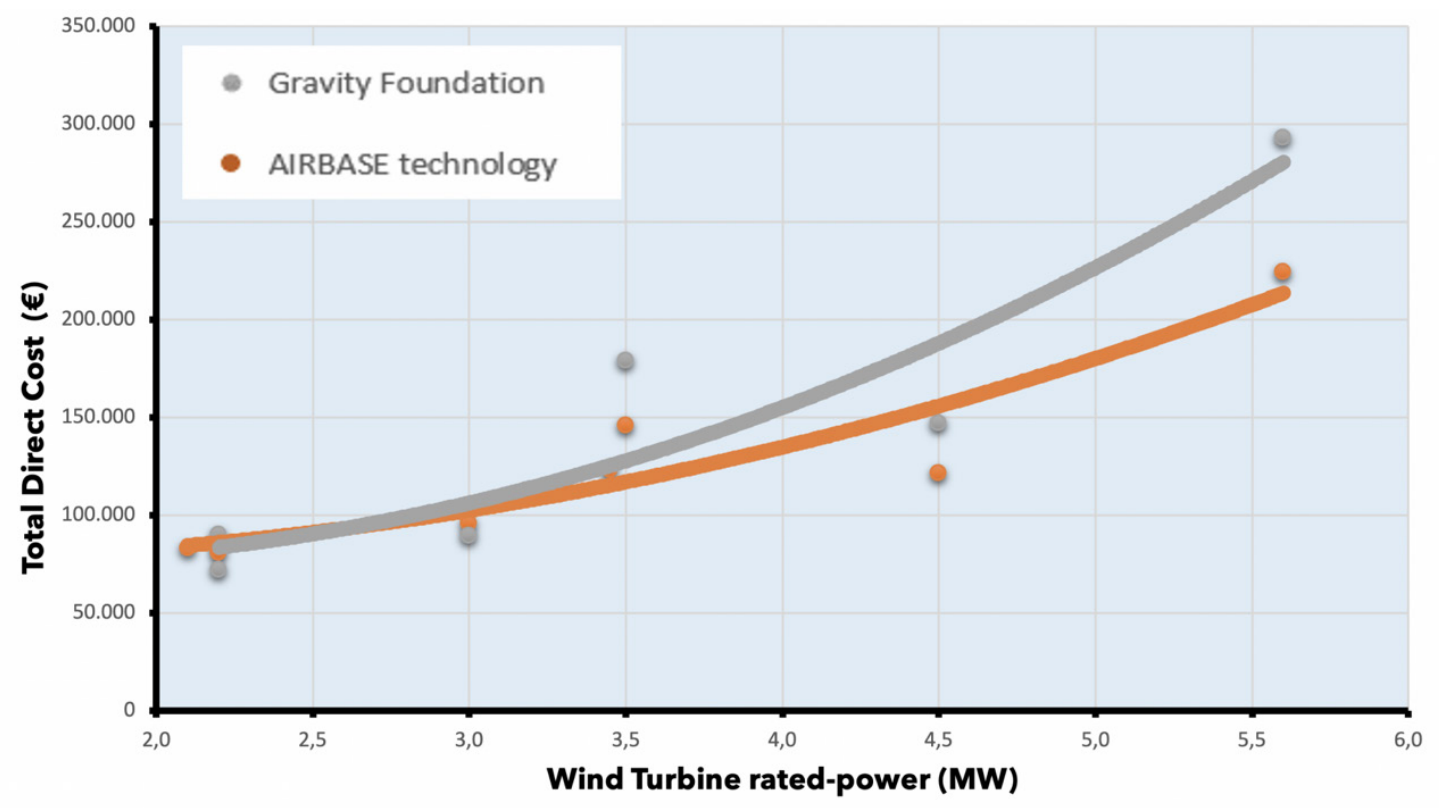

Figure 23. Total foundation cost comparison: gravity (spread-foot) foundation vs. AirBASE technology. Image from HWS Concrete Towers (undated)

\subsection{Wind Turbine Erection}

We did not explore alternative wind turbine erection technologies and innovations for the single $20-\mathrm{kW}$ wind turbine project. As discussed in Section 2, the cost of wind turbine erection and installation calculated by LandBOSSE was $\$ 245 / \mathrm{kW}$, which is roughly $\sim 8 \%$ of the total BOS CapEx of the single $20-\mathrm{kW}$ wind turbine project. This low cost is because of the inexpensive rental and mobilization of smaller truck cranes required for the turbine erection and installation. The engineering and cost estimates for the 20-kW machine discussed in Section 2 are for a freestanding monopole tower, which is only one of the three main tower types available commercially. The other two tower types are guyed and lattice towers (Figure 24). 


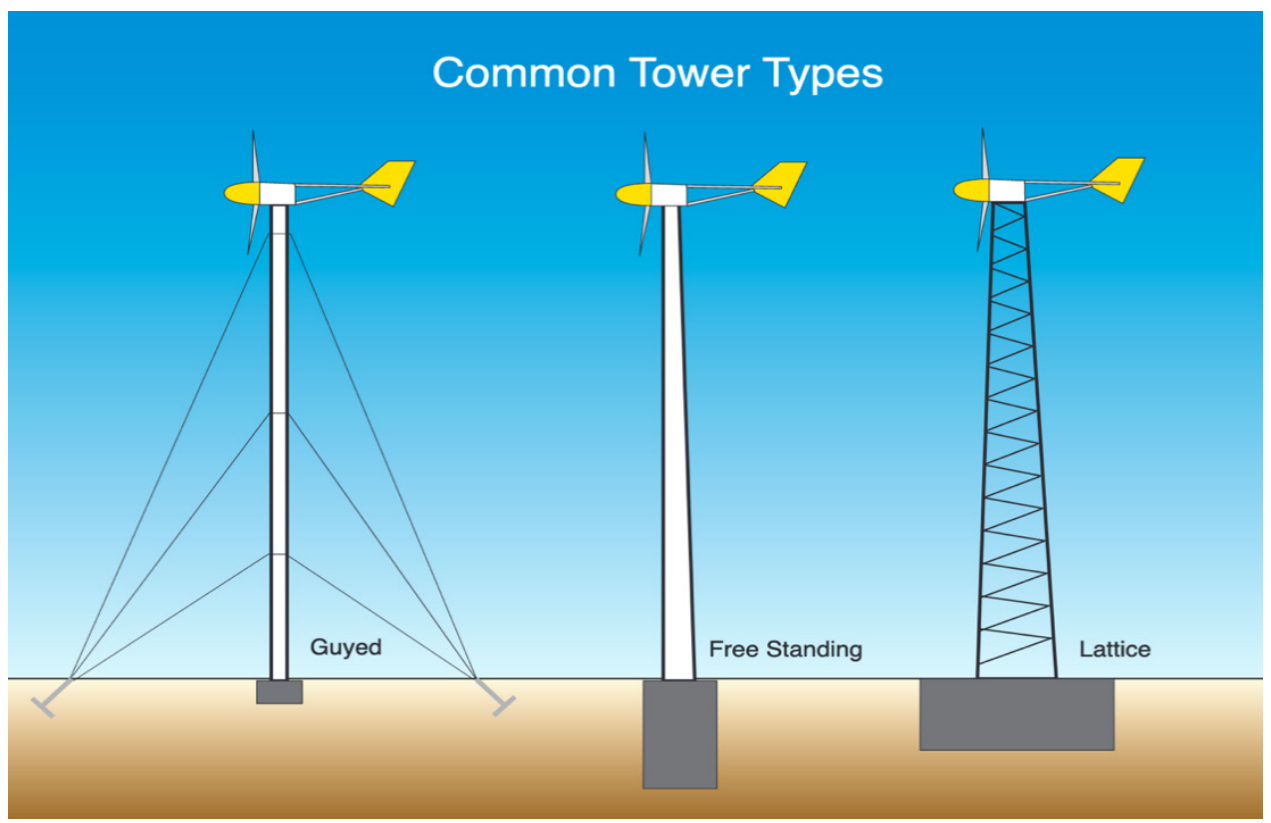

Figure 24. Most common wind turbine tower types available at the residential scale $(<100 \mathrm{~kW})$. Image from Northwestern Energy (2015)

The lattice tower is the most common type currently used for residential-scale applications because of its smaller footprint and lack of guy wires. In the past, the guyed tower was the most popular as a result of its lower costs. Incentive programs that reduce CapEx led consumers to prefer the more expensive self-supporting lattice towers.

Tower erection and installation is the third-biggest BOS cost for a $100-\mathrm{kW}$ wind turbine project, and it represents roughly $\sim 12 \%$ of the turbine's BOS CapEx. The biggest cost drivers within the erection cost bucket are labor cost (45\% of total tower erection cost), and crane rental cost (50\% of total tower erection cost). Pecos Wind Power is currently studying the viability of a hydraulic (telescopic) tilt-up tower. Previously employed primarily at the residential-scale, tilt-up telescopic towers are now being explored for the commercial-scale turbine (21- to $100-\mathrm{kW}$ machine rating) projects. Tilt-up towers for commercial-scale turbines would allow for cranefree turbine erection, ground-based turbine assembly, and optimized transportation of the turbine and tower components, thereby reducing assembly time, reducing BOS costs, and providing easier access to remote locations and crane-free operation and maintenance activities. With these possibilities in mind, telescopic tilt-up towers could reduce wind turbine erection costs by $95 \%$. However, this innovation is still in its early research and development stage.

When considering the conventional erection strategy (Eberle et al. 2019) discussed in Section 2.2.4, running LandBOSSE for the $650-\mathrm{kW}$ wind turbine scenarios, the total tower erection installation cost is estimated to be $\$ 76,401$ (or $\$ 116 / \mathrm{kW}$ ). Similarly, when considering the conventional erection strategy, running LandBOSSE for the single 1,500-kW wind turbine scenario, the total tower erection installation cost is estimated to be $\$ 251,603$ (or $\$ 168 / \mathrm{kW}$ ).

Figure 25 and Figure 26 break down the cost of wind turbine erection by type. As turbines get bigger and taller, the crane required for tower erection and installation shifts from easy-tomobilize hydraulic/truck cranes with telescopic booms to the larger crawler cranes with lattice 
booms. Lattice boom crawler cranes are designed to lift heavier loads than hydraulic cranes with telescopic booms.

As shown in Figure 25 and Figure 26, crane mobilization (and demobilization) cost is the biggest share of the tower erection cost bucket. Hydraulic and truck cranes (used in the 20-kW and 100$\mathrm{kW}$ wind turbine projects) have a very low mobilization cost but a relatively higher rental cost. In comparison, the larger, crawler cranes with lattice booms (used in the $650-\mathrm{kW}$ and $1,500-\mathrm{kW}$ wind turbine projects) have a high mobilization cost but a low rental cost. Crane mobilization cost here refers to all costs associated with crane unloading, loading, assembly, disassembly, walking, reconfiguration, and transportation to the project site.

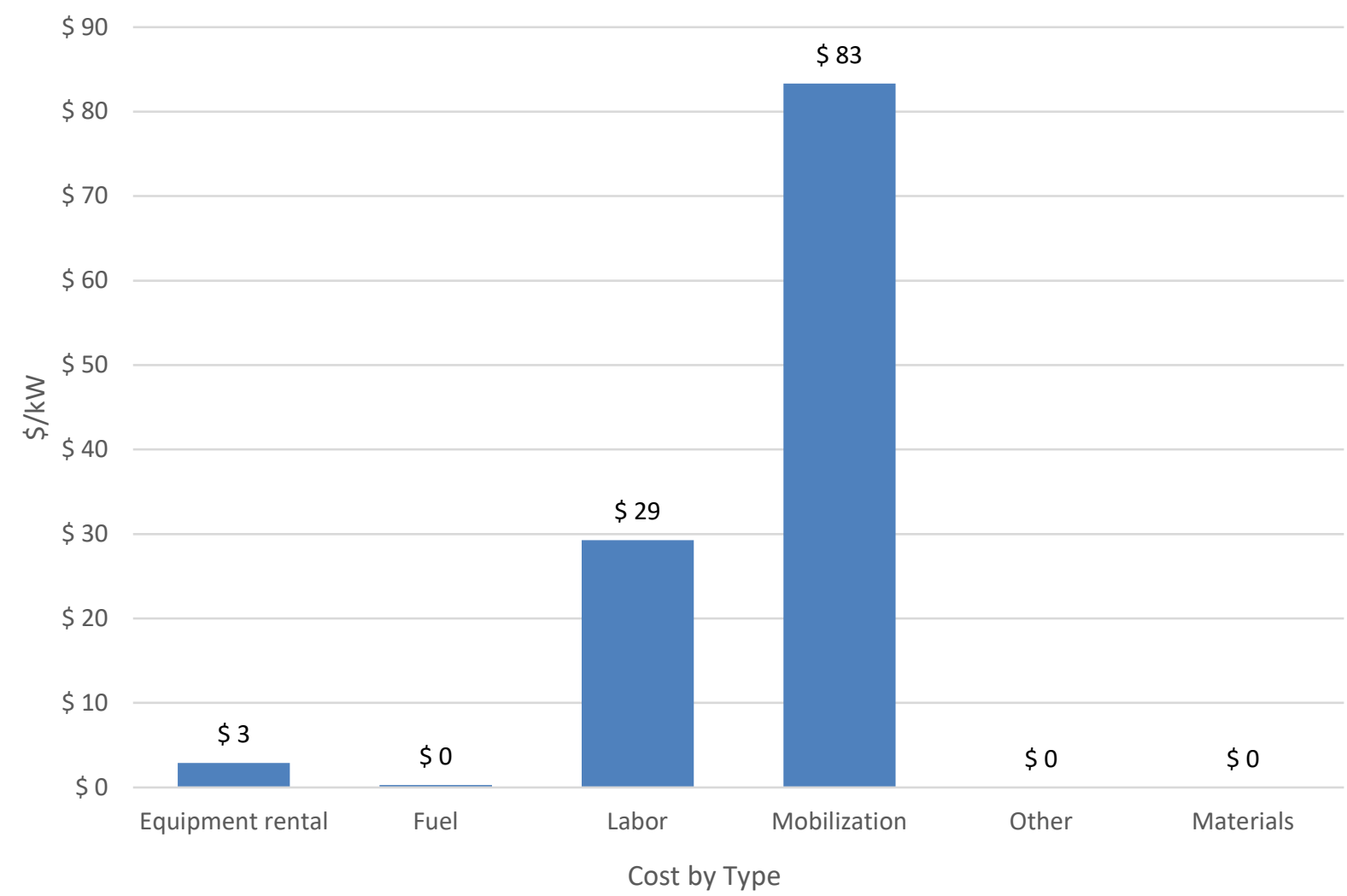

Figure 25. Cost breakdown of erecting a single $650-\mathrm{kW}$ wind turbine by type of cost 


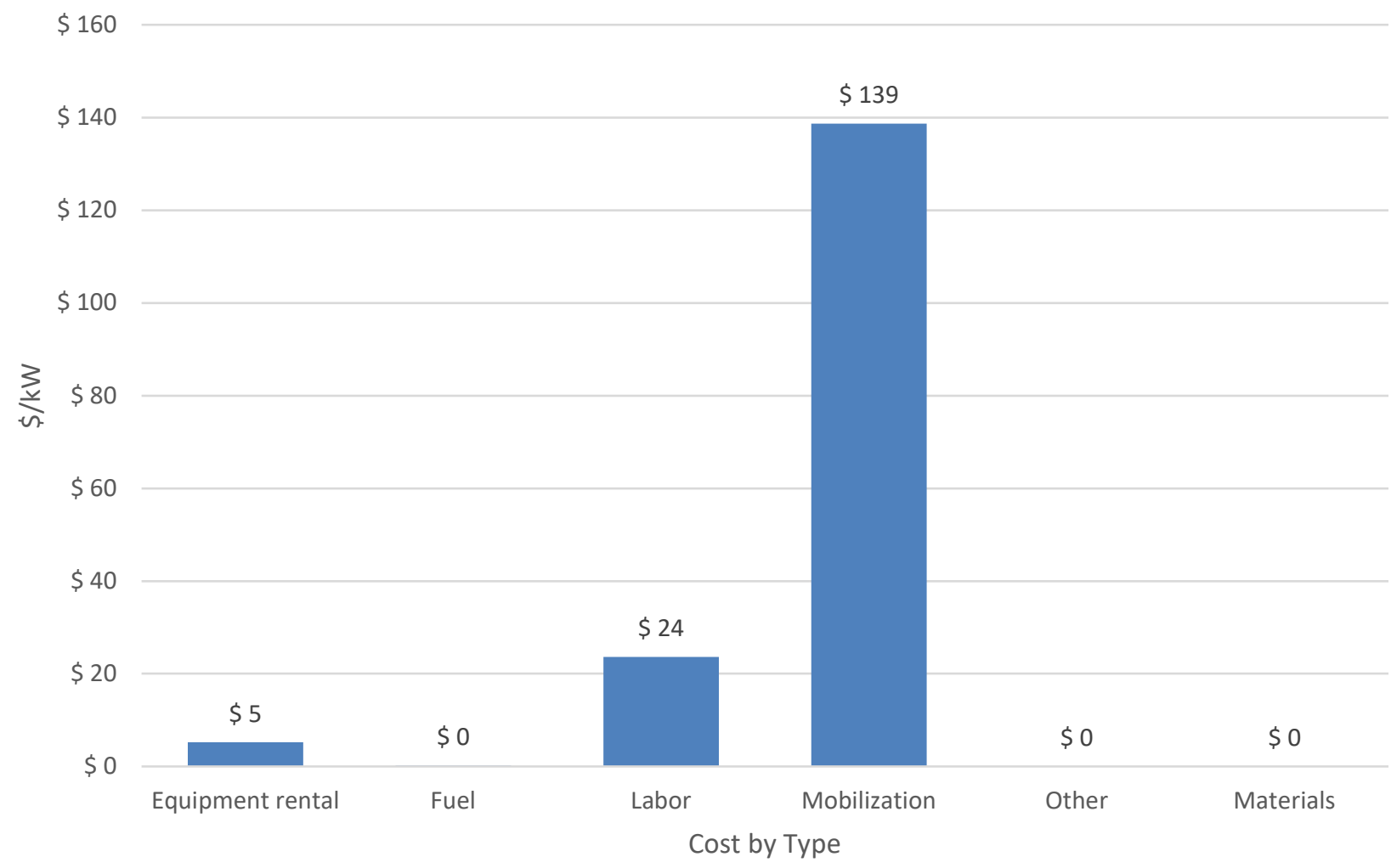

Figure 26. Cost breakdown of erecting a single 1,500-kW wind turbine by type of cost

A promising alternative erection strategy considered in this section for the mid and large turbine sizes is Liftra's self-climbing crane system. ${ }^{9}$ Liftra announced in early 2020 their plans to develop a new type of crane, the LT1500. They claim that the self-climbing crane can erect/install all the components of a wind turbine (including the tower sections, nacelle, and rotor) and is capable of erecting entire wind turbines without the need for larger, conventional crawler cranes. Liftra currently offers similar alternative crane technologies like the self-hoisting crane, LT1000, as shown in Figure 27. Per Liftra, the self-climbing cranes fit in shipping containers and are therefore easily transportable to the project site. A self-climbing crane system has the potential to reduce the large costs and labor hours associated with mobilizing and demobilizing the crane on-site.

Based on a total cost estimation provided by Liftra, their self-climbing system has the potential to reduce wind turbine erection and installation cost by roughly $60 \%$ for the large turbine $(1,500$ $\mathrm{kW}$ turbine rating and up). ${ }^{10}$ It is still uncertain whether the Liftra self-climbing crane system will offer any economic benefits for the midsize turbine.

${ }^{9}$ The proposed self-climbing wind turbine erection technology is different from the current commercially available self-hoisting crane technology. Self-climbing cranes are currently still in the research and development phase, and the alleged techno-economic benefits claimed by Liftra are yet to be proven/demonstrated.

${ }^{10}$ A project will still need a crane to erect the first 15 meters of the tower for the self-climbing crane to begin its climb up the wind turbine. 


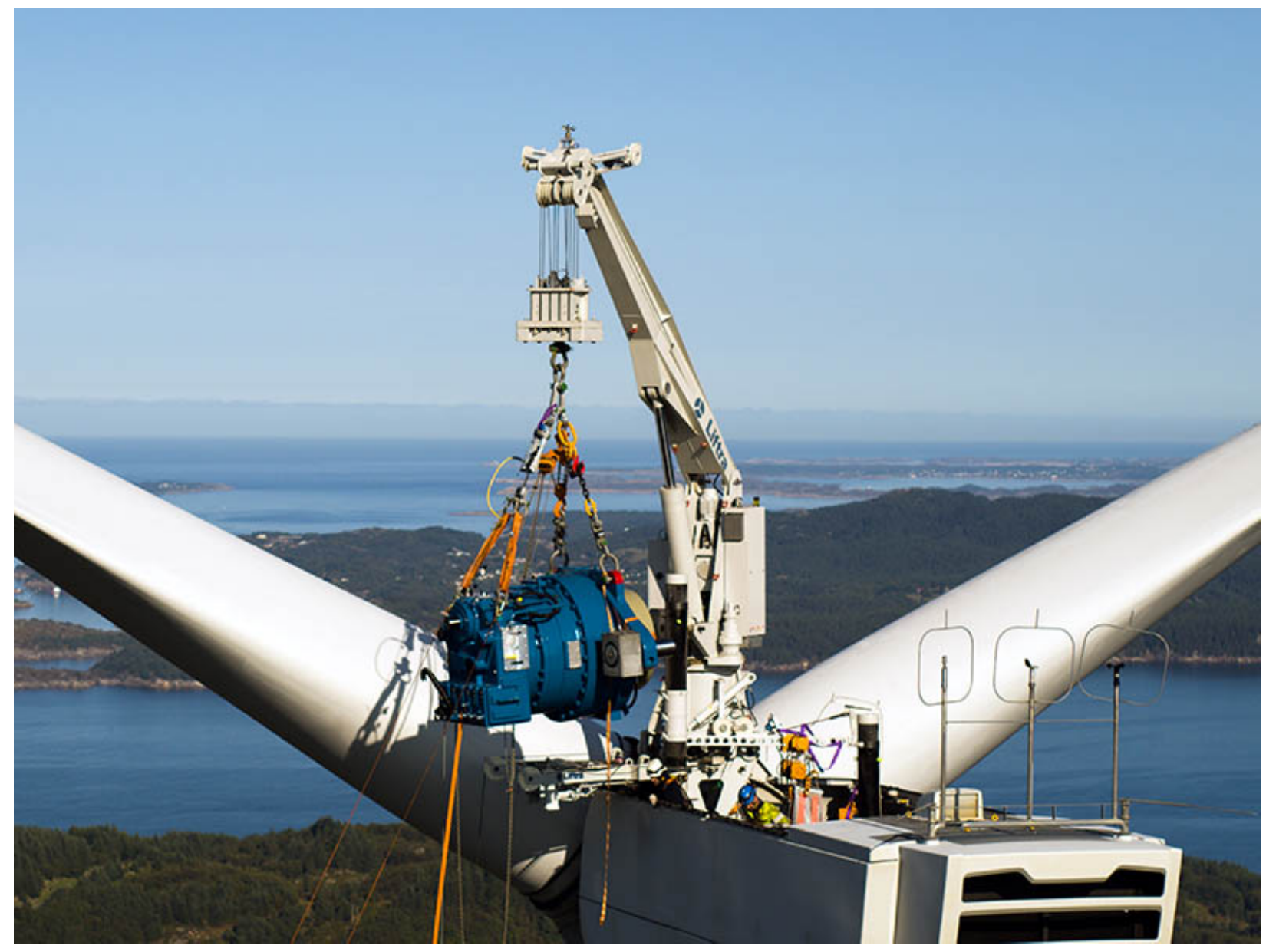

Figure 27. Liftra's self-hoisting crane capable of changing major wind turbine components. Photo from Liftra (undated)

\subsection{Grid Connection}

The grid connection module of LandBOSSE currently implements a curve fit of industry data in estimating the grid interconnection cost of a project. The industry data include costs pertaining to performing a land survey, clearing and grubbing the area, implementing stormwater pollution measures, installing the poles, installing the conductor, procuring and installing transformers and switchgear, and restoring the right of way. Note that the grid connection cost discussed in this section is primarily focused on the larger turbine projects (midsize and large). For commercialand residential-scale projects, grid connection costs are relatively lower than the other BOS modules.

For front-of-the-meter distributed wind projects, accurately estimating a project's grid connection cost is a complex task and is highly dependent on the case, resulting in total grid connection costs varying greatly from project to project. ${ }^{11}$ The grid connection cost equation in LandBOSSE is a curve fit of proprietary industry data, which was developed using mean cost values across multiple ranges of wind turbine sizes (residential, commercial midsize, and large

${ }^{11}$ This report assesses the grid connection cost of a mix of front-of-the-meter and behind-the-meter projects. 
turbine ratings). Therefore, grid connection cost calculated by LandBOSSE, and as discussed in Section 2, is a median representation of the expected grid interconnection costs of distributed wind projects. At a high level, grid connection cost depends on the project's terrain complexity and availability of existing infrastructure (civil and electrical). Overhead installation, procurement, and construction of a step-up transformer and switchgear, and medium-voltage cable terminations can make up more than half of the grid connection cost of a distributed wind project.

The electrical infrastructure connecting the distributed wind project to the distribution network can be broken down into three main costs: spur transmission (gen-tie line), point of interconnection, and bulk transmission ${ }^{12}$ (Figure 28).
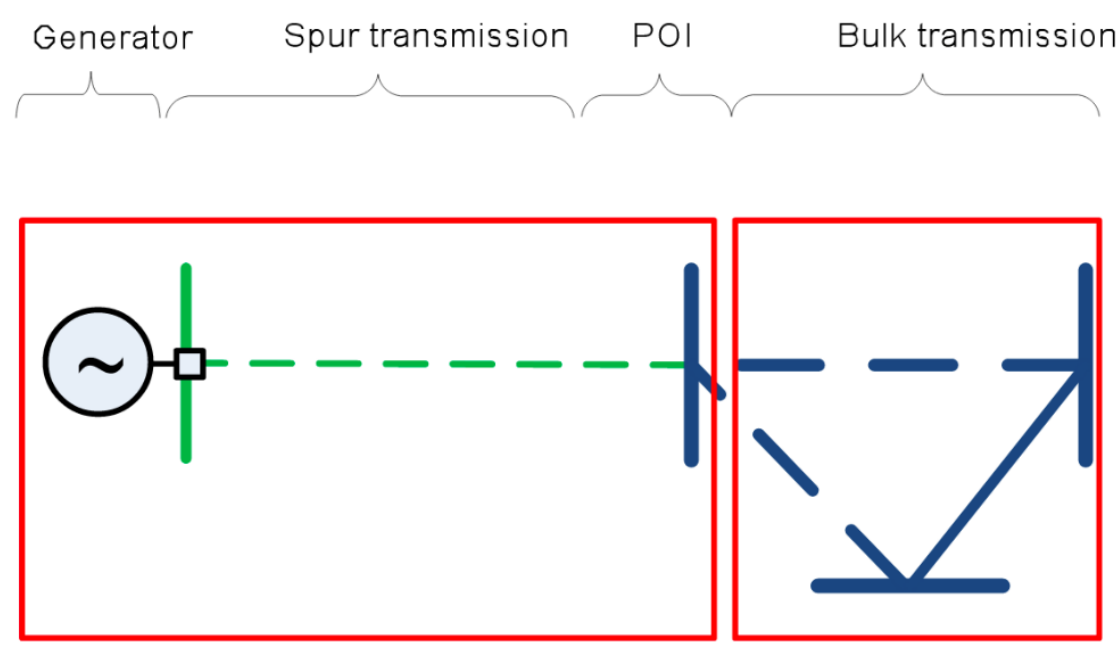

$\overline{\text { New }}$ spur line

New bulk transmission

Existing bulk transmission

Figure 28. Transmission cost parts for new generation projects. Image from Andrade (2016)

Note: point of interconnection (POI)

For the mid and large-scale wind turbine projects modeled in LandBOSSE, we assumed the grid interconnection voltage to be 15 kilovolts, with overhead transmission construction; accordingly, the three main cost drivers identified for these distributed wind scenario were (1) land and construction costs, ${ }^{13}(2)$ extent of transmission construction/upgrades needed between the generator and the grid distribution system, ${ }^{14}(3)$ and location of the wind turbine generator and the length of upgrades needed (Andrade 2016).

Land costs depend on the cost of land where the project is geographically located; with the cost of land being cheaper in states like Texas, compared to states in the northeastern United States. Furthermore, terrain complexity (urban area, mountainous region, and/or rolling hills) dictates

\footnotetext{
${ }^{12}$ Bulk transmission here is not part of the distribution network. However, there may be situations when the distributed wind project developer/owner has to cover some or all of the bill of any transmission network upgrade required for hosting a larger project.

${ }^{13}$ Includes road crossing, trenching, overhead installation, engineering, supervisory control and data acquisition, interconnect boring, and so on.

${ }^{14}$ Includes a step-up transformer, switchgear, medium-voltage cable termination, wiring, and so on.
} 
the length and route of the spur transmission (see Figure 28) from the wind turbine generator to the point of interconnection, as well as costs associated with access road, road crossings, trenching, overhead installation, and so on.

Identifying the extent of transmission construction/upgrades between the wind turbine generator and the utility's distribution system is again case-dependent. For instance, projects sited behind the meter to meet partial on-site load, or on brownfield sites for front-of-the-meter application (locations that previously had a generator that was decommissioned ever since) would require minimal to no upgrades to the transmission infrastructure, as identified in Figure 28. So, a pathway for reducing BOS CapEx of future distributed wind projects would be an exhaustive identification of favorable behind-the-meter, front-of-the-meter, and brownfield sites in the United States, and/or a very detailed geospatial mapping of the country's distribution grid and identifying transmission infrastructure requiring little-to-no transmission upgrades paid for by the project developer.

Moreover, some projects might require upgrades to the bulk transmission system, the cost of which is often covered (in full, or partially) by the project developer as well. In such cases, incentivizing deployment of wind turbine generators for distributed wind applications by subsidizing cost to the developer of bulk transmission upgrades would serve as a potential pathway for lowering grid interconnection costs. In closing, as discussed in the sensitivity analyses in Section 2, reducing grid interconnection cost by $30 \%$ can lower the project BOS CapEx by up to $13 \%$ for the midsize and large wind turbine projects (single- and five-turbine installations). 


\section{Conclusions and Future Work}

This exploratory analysis on BOS cost reduction opportunities for residential, commercial, midsized, and large distributed wind systems evaluated not only the opportunity space for reducing BOS system costs but provided an assessment of particular technologies and their potential to achieve BOS cost reductions. After completing these two primary assessments to evaluate the opportunity space and executing a qualitative evaluation for the specific technology pathways (and quantifying their impacts where possible) to achieve cost reductions, we were able to identify specific BOS cost categories and technologies that may offer the greatest cost reductions for total BOS costs.

During this work, we captured the results of the sensitivity analysis and identified the BOS cost categories that have the greatest impact on reducing total BOS costs over the set of six distributed wind system scenarios defined in Section 2.1. A summary of the primary sensitivity findings for each of the six scenarios includes the following:

- The project management and development ${ }^{15}$ cost is the highest BOS cost for a single-turbine residential project $(20 \mathbf{~ k W})$. We estimated around $\$ 1,376 / \mathrm{kW}$ for the baseline; therefore, reducing management costs by $30 \%$ reduces total BOS costs by more than $13 \%$, thereby reducing the total BOS cost from $\$ 3,100 / \mathrm{kW}$ to $\$ 2,697 / \mathrm{kW}$. The foundation cost of the residential system also shows a significant reduction of total BOS, theoretically by $11 \%$, assuming $30 \%$ of foundation costs can be removed from the project.

- The single-turbine, commercial $(100 \mathrm{~kW})$ distributed system costs are driven by project management and development cost. We used a baseline estimate of $\$ 757 / \mathrm{kW}$; therefore, by reducing the management cost by $30 \%$, total BOS costs are reduced by $13 \%$, thereby bringing the cost down to $\$ 1,540 / \mathrm{kW}$ from $\$ 1,770 / \mathrm{kW}$. Reducing the wind turbine foundation cost by $30 \%$ has the next largest reduction of total BOS costs by $11 \%$.

- The cost of grid connection becomes a significant cost component for the midsize single-turbine $(650 \mathrm{~kW})$ system. Reducing the baseline cost $(\$ 297 / \mathrm{kW})$ by $30 \%$ changes the total BOS cost by $10.5 \%$ (from $\$ 870 / \mathrm{kW}$ to $\$ 780 / \mathrm{kW}$ ). Additionally, reducing the management and development cost by $30 \%$ results in a reduction of total BOS costs by $10.2 \%$.

- The single-turbine large $(1,500 \mathrm{~kW})$ system has a higher project management and development cost than the other cost categories. We obtained $\$ 400 / \mathrm{kW}$ for the baseline from proprietary industry data; hence, reducing this cost by $30 \%$ reduces the BOS cost by more than $14.5 \%$, from $\$ 950 / \mathrm{kW}$ to $830 / \mathrm{kW}$. Following the BOS reduction potential of the project management and development costs are the site preparation and grid connection costs, showing a reduction of total BOS cost around $6 \%$.

- The grid connection cost drives the total BOS costs when installing five midsized $(650 \mathrm{~kW})$ wind turbines. Reducing the grid connection cost by $30 \%$ from the baseline $\$ 192 / \mathrm{kW}$ estimate brings down total BOS cost by about $12.7 \%$, decreasing from $\$ 453 / \mathrm{kW}$ to $\$ 395 / \mathrm{kW}$.

\footnotetext{
${ }^{15}$ Management and development cost in our analysis consist of costs pertaining to (1) construction management, (2) other management and development, (3) engineering and design, and (4) ZPII.
} 
- The BOS cost for installing five large $(1,500 \mathrm{~kW})$ wind turbines is most highly influenced by grid connection costs. By reducing the grid connection costs by $30 \%$ (base case $\$ 153 / \mathrm{kW}$ ), total BOS cost is reduced by about $11.2 \%$ from the five-turbine baseline estimate, decreasing from $\$ 455 / \mathrm{kW}$ to $\$ 410 / \mathrm{kW}$.

A summary of the results of the sensitivity analysis for the six scenarios is provided in Table 11 and Table 12.

\section{Table 11. Percent Reduction of Total Project BOS Cost Assuming 30\% Reduction in Respective BOS Component Cost}

\begin{tabular}{|c|c|c|c|c|c|}
\hline $\begin{array}{l}\text { System Size } \\
(\mathrm{kW})\end{array}$ & $\begin{array}{l}\text { Collection } \\
\text { System }\end{array}$ & $\begin{array}{l}\text { Tower } \\
\text { Erection }\end{array}$ & $\begin{array}{l}\text { Turbine } \\
\text { Foundation }\end{array}$ & $\begin{array}{l}\text { Grid } \\
\text { Connection }\end{array}$ & $\begin{array}{l}\text { Management \& } \\
\text { Development } \\
\text { Cost }\end{array}$ \\
\hline
\end{tabular}

\begin{tabular}{|c|c|c|c|c|c|c|}
\hline $\begin{array}{l}\text { Residential } \\
\text { (20) }\end{array}$ & 1 & 2 & 11 & 1 & 13 & 2 \\
\hline $\begin{array}{c}\text { Commercial } \\
(100)\end{array}$ & 1 & 4 & 11 & 1 & 13 & 1 \\
\hline $\begin{array}{c}\text { Midsize } \\
(650)\end{array}$ & $<0.5$ & 3.9 & 2.5 & 10.2 & 10.2 & 1.9 \\
\hline $\begin{array}{l}\text { Large } \\
(1,500)\end{array}$ & $<0.5$ & 5.5 & 3.6 & 8 & 14.5 & 1 \\
\hline $\begin{array}{c}5 \times \text { Midsize } \\
(5 \times 650)\end{array}$ & 1.37 & 3.2 & 5.5 & 12.7 & 3.9 & 3.4 \\
\hline $\begin{array}{c}5 \times \text { Large } \\
(5 \times 1,500)\end{array}$ & 0.9 & 4.9 & 6.6 & 11.2 & 5.6 & 1.6 \\
\hline
\end{tabular}

Note: (1) Highest cost reduction potential

(2) Second highest cost reduction potential

Table 12. Summary of Largest Cost Reduction Drivers of Balance-of-System Costs

\begin{tabular}{c|c|c|c|c|c|}
$\begin{array}{c}\text { Scenario } \\
\text { Number }\end{array}$ & $\begin{array}{c}\text { Number of } \\
\text { Turbines }\end{array}$ & $\begin{array}{c}\text { Turbine } \\
\text { Rating } \\
(\mathrm{kW})\end{array}$ & $\begin{array}{c}\text { System } \\
\text { Size }(\mathrm{kW})\end{array}$ & $\begin{array}{c}\text { Leading Cost Reduction } \\
\text { Category }\end{array}$ & $\begin{array}{c}\text { Total BOS Cost } \\
\text { Reduction }(\%)\end{array}$ \\
\hline $\mathbf{1}$ & 1 & 20 & 20 & $\begin{array}{c}\text { Project management and } \\
\text { development }\end{array}$ & 13 \\
\hline $\mathbf{2}$ & 1 & 100 & 100 & $\begin{array}{c}\text { Project management and } \\
\text { development }\end{array}$ & 13 \\
\hline $\mathbf{3}$ & 1 & 650 & 650 & Grid connection & 10.2 \\
\hline $\mathbf{4}$ & 1 & 1,500 & 1,500 & $\begin{array}{c}\text { Project management and } \\
\text { development }\end{array}$ & 14.5 \\
\hline $\mathbf{5}$ & 5 & 650 & 3,250 & Grid connection & 12.7 \\
\hline $\mathbf{6}$ & 5 & 1,500 & 7,500 & Grid connection & 11.2 \\
\hline
\end{tabular}

Note: For leading cost reduction categories, listing more than one category for a single scenario resulted in similar total BOS cost reductions. 
The largest BOS cost-driving components, as shown in Table 11 and Figure 29, are wind turbine foundation, management and development, and grid interconnection. See Section 3 for a discussion of technological innovations that could reduce BOS costs of distributed wind projects.

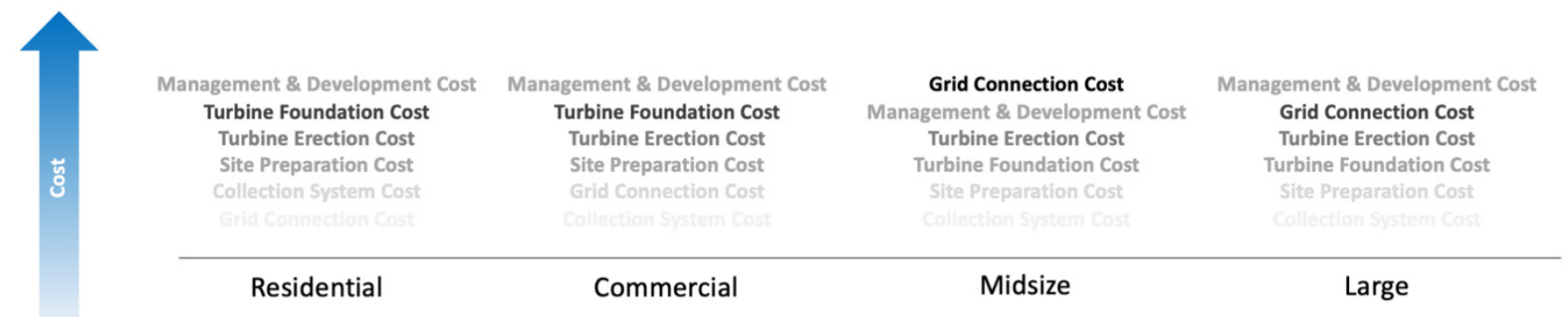

Figure 29. Increasing order of BOS cost contributors at each wind turbine scale

Notes:

- Management and development cost for the residential and commercial-scale projects were obtained from the Pacific Northwest National Laboratory's 2017 report, "Benchmarking U.S. Small Wind Costs" (Orrell and Poehlman 2017). This cost driver comprises ZPII, engineering and design, overhead and markup, and "other" costs.

- Management and development cost numbers for mid and large-size distributed wind projects from industryreported proprietary costs. However, the sample size of the data used to derive management and development costs for the mid and large-size turbines was very limited, consisting of three projects each for both mid and large size turbine projects.

- $\quad$ Therefore, the management and development cost was greyed out in each of the turbine scales to shift focus to other cost-driving components for which analysts reviewed pathways for cost reduction in Section 2.

In this report, the scope of exploring cost reduction opportunities for a distributed wind project was limited to a project's BOS component. However, there are additional innovation pathways not considered in this study that have the potential to reduce total BOS costs. Some instances of such non-BOS innovations include hybridizing a "distributed wind only" project by adding solar photovoltaics to the mix. Benefits of co-locating distributed wind and solar include a higher capacity factor (more energy produced per kilowatt of project capacity) and therefore higher system reliability and sharing infrastructure (like the cabling system, grid interconnection, and so on). Hybridization also provides benefits during the construction phase of a project, such as sharing construction labor, materials, and equipment between the two technologies (wind and solar), as well as sharing soft costs like management, ZPII, development, and so on.

Another area not explored in this report but worth considering is the promise of innovations in wind turbine tower technologies. Technological innovations such as hybrid towers are gaining momentum because of the high costs associated with erecting the conventional sectional steel monopole towers (driven primarily by high costs of larger cranes, as covered in Sections 2 and 3). Hybrid towers includes new solutions like towers that have a bottom half made from concrete that is three dimensionally printed on-site and an upper half made from conventional steel. Another technology being explored in commercial-scale wind turbine projects is tilt-up telescopic towers. Previously employed primarily at the residential scale, tilt-up telescopic towers are being explored for commercial-scale wind power projects (21- to $100-\mathrm{kW}$ machine rating). Tilt-up towers for commercial-scale wind turbines will allow for crane-free turbine 
erection, ground-based turbine assembly, and optimized transportation of the turbine and tower components; thereby reducing assembly time and BOS costs ${ }^{16}$ and providing easier access to remote locations and crane-free operation and maintenance activities.

${ }^{16}$ There is the potential caveat that a tilt-up tower would translate to a higher tower cost because it needs to be made stronger to withstand the higher loads experienced during tilt-up. 


\section{References}

Andrade, J., R. Baldick. 2016. Estimation of Transmission Costs for New Generation.

http://sites.utexas.edu/energyinstitute/files/2016/11/UTAustin_FCe_TransmissionCosts_2016.pd f.

Bergey, M. 2018. Lowering the Time and Costs of Small Wind Installations. Small Wind Conference. Bergey Windpower. http://smallwindconference.com/wpcontent/uploads/2018/04/26-Lowering-the-Time-and-Costs-of-Small-Wind-Installations-1.pdf.

Eberle, Annika, Owen Roberts, Alicia Key, Parangat Bhaskar, and Katherine Dykes. 2019. NREL's Balance-of-System Cost Model for Land-Based Wind (Technical Report). Golden, CO: National Renewable Energy Laboratory. NREL/TP-6A20-72201. https://www.nrel.gov/docs/fy19osti/72201.pdf.

HWS Concrete Towers. Undated. http://www.hwstowers.com/.

Lantz, E., B. Sigrin, M. Gleason, R. Preus, I. Baring-Gould. 2016. Assessing the Future of Distributed Wind: Opportunities for Behind-the-Meter Projects (Technical Report). Golden, CO: National Renewable Energy Laboratory (NREL). TP-6A20-67337.

https://www.nrel.gov/docs/fy17osti/67337.pdf.

Liftra. Undated. https://liftra.com/.

Michel, P. Christoph B., Sven K. 2018. "Pile-grid foundations of onshore wind turbines considering soil-structure-interaction under seismic loading." Soil Dynamics and Earthquake Engineering, Vol. 109, pp. 299-311.

https://www.sciencedirect.com/science/article/pii/S0267726117307571.

Northwestern Energy. 2015. The Montana Consumer Guide to Small Wind Generation Systems. https://www.northwesternenergy.com/docs/default-source/documents/e-programs/mt-consumerguide-to-small-generation-wind-systems.

Orrell, A., and E. Poehlman. 2017. Benchmarking U.S. Small Wind Costs With the Distributed Wind Taxonomy. Pacific Northwest National Laboratory (PNNL). https://www.pnnl.gov/publications/benchmarking-us-small-wind-costs-distributed-windtaxonomy.

Sunrun. 2010. The Impact of Local Permitting on the Cost of Solar Power. https://www.sunrun.com/solar-lease/cost-of-solar/localpermitting\#: : text=Streamlined $\% 20$ permitting $\% 20$ can $\% 20$ make $\% 20$ solar,to $\% 20$ the $\% 20$ cost $\% 2$ 0of\%20solar.

Wesoff, E. 2011. "Dropping Solar Costs by $\$ 0.50$ Per Watt With Smart Permits." https://www.greentechmedia.com/articles/read/sunrun. 